\title{
Neuroimaging Support for Discrete Neural Correlates of Basic Emotions: A Voxel-based Meta-analysis
}

\author{
Katherine Vytal and Stephan Hamann
}

\begin{abstract}
What is the basic structure of emotional experience and how is it represented in the human brain? One highly influential theory, discrete basic emotions, proposes a limited set of basic emotions such as happiness and fear, which are characterized by unique physiological and neural profiles. Although many studies using diverse methods have linked particular brain structures with specific basic emotions, evidence from individual neuroimaging studies and from neuroimaging meta-analyses has been inconclusive regarding whether basic emotions are associated with both consistent and discriminable regional brain activations. We revisited this question, using activation likelihood estimation (ALE), which allows spatially sensitive, voxelwise statistical comparison of results from multiple studies. In addition, we examined substantially more studies than previous meta-analyses. The ALE meta-analysis yielded results consistent
\end{abstract}

\section{INTRODUCTION}

Emotions are a key facet of human experience. A central question in the study of emotion is how best to characterize the basic structure of emotional experience. Discrete emotion theories (Ekman, 1972; Darwin, 1872) propose a limited set of basic emotions (e.g., happiness, sadness, anger, fear, and disgust) that have unique physiological and neural profiles. Other theoretical views, such as dimensional theories of emotion, conceptualize emotions using a framework in which affective states can be represented in terms of underlying factors such as emotional arousal (emotion strength) and emotional valence (degree of pleasantness or unpleasantness).

A key proposal of basic emotion theories is that basic emotions have consistent and specific psychophysiological and neural correlates. Ekman (1999) summarized this view: "It is necessary to posit emotion-specific central nervous system (CNS) activity in my account of basic emotions. The distinctive features of each emotion, including the changes not just in expression but in memories, imagery, expectations and other cognitive activities, could not occur without central nervous system organization and direction. There must be unique physiological [CNS] patterns for each emotion (p. 50)". Although the predic-

Emory University with basic emotion theory. Each of the emotions examined (fear, anger, disgust, sadness, and happiness) was characterized by consistent neural correlates across studies, as defined by reliable correlations with regional brain activations. In addition, the activation patterns associated with each emotion were discrete (discriminable from the other emotions in pairwise contrasts) and overlapped substantially with structure-function correspondences identified using other approaches, providing converging evidence that discrete basic emotions have consistent and discriminable neural correlates. Complementing prior studies that have demonstrated neural correlates for the affective dimensions of arousal and valence, the current meta-analysis results indicate that the key elements of basic emotion views are reflected in neural correlates identified by neuroimaging studies.

tions of basic emotion theories have drawn support from a wide variety of behavioral, neuropsychological, psychophysiological, and neuroimaging studies (e.g., Damasio et al., 2000; Blair, Morris, Frith, Perrett, \& Dolan, 1999; Ekman, 1992), recently the strength of the support for basic emotion theories has been challenged (e.g., Barrett, Lindquist, Bliss-Moreau, Duncan, \& Brennan, 2007; Barrett \& Wager, 2006; Barrett \& Russell, 1999). For example, reviews of the psychophysiological literature have concluded that such studies have not been able to identify consistent and specific psychophysiological correlates for basic emotions (Barrett \& Wager, 2006; Cacioppo, Berntson, Larsen, Poehlmann, \& Ito, 2000; Zajonc \& McIntosh, 1992).

Neuroimaging studies can assess activity related to emotional states across the entire brain on a moment-tomoment basis, and thus one might expect that this approach would be more sensitive and better able to identify the consistent and specific biological correlates for basic emotions than other measures such as behavior or psychophysiology. However, the strength and the consistency of the neuroimaging evidence supporting the predictions of basic emotion theories have also been questioned, and some critiques have concluded that evidence for basic emotions from neuroimaging remains inconclusive (Barrett \& Wager, 2006; Barrett \& Russell, 1999). The existing literature directly relevant to evaluating whether basic emotions have differentiable neural correlates is relatively limited, in 
part because only a handful of neuroimaging studies have examined and contrasted several basic emotions concurrently in the same study. Meta-analytic methods applied to the neuroimaging literature can help overcome this limitation in the available corpus of literature because such methods allow activation patterns to be compared across different studies. Such techniques can identify neural patterns that are consistent and specific to each emotion state. Meta-analyses can also assess whether these activation patterns are robust across experimental differences such as type of emotional stimuli and emotion-elicitation methods, and they can reduce problems associated with low experimental power in individual studies (Ioannidis \& Lau, 1999).

Two meta-analytic reviews of the relevant basic emotion neuroimaging literature have been conducted to date (Murphy, Nimmo-Smith, \& Lawrence, 2003; Phan, Wager, Taylor, \& Liberzon, 2002; for additional meta-analytic reviews of the neural correlates of emotion, but not basic emotion states, see also Kober et al., 2008; Baas, Aleman, \& Kahn, 2004; Wager, Phan, Liberzon, \& Taylor, 2003). Both Phan et al. (2002) and Murphy et al. (2003) concluded that basic emotion theories are only partially supported by neuroimaging studies, and each review reached somewhat different conclusions regarding which specific neural correlates are associated with each basic emotion (Barrett \& Wager, 2006). Because the status of the neuroimaging evidence supporting basic emotion theories is currently unresolved, we revisited these questions in the current meta-analytic study. We hypothesized that by using a more sensitive meta-analytic method (activation likelihood estimation; ALE, Laird et al., 2005) than those used in previous reviews and by analyzing a substantially larger number of neuroimaging studies that have been published in the several years following the publication of these earlier reviews, we could potentially reveal differences between basic emotion states that were not detected in previous studies.

The current study differs from previous meta-analytic reviews in two primary respects: the meta-analytic methodology used and the number of studies included. We used the ALE method, which preserves three-dimensional spatial information in the original activation maximum coordinate data, unlike label-based methods that convert activation coordinates into regional labels (e.g., pFC), decreasing spatial information considerably. ALE allows for direct statistical comparison between the composite activation maps associated with discrete emotion states and thus provides a means for assessing the discriminability of basic emotion states at the voxel level. Although the analysis used by Murphy et al. (2003) did assess the differentiability of neural patterns associated with basic emotions states, their meta-analysis method divided the brain into only eight sectors of approximately equal volume. These sectors are larger than individual brain structures and are orders of magnitude less spatially specific than the voxel level resolution afforded by ALE. Thus, this prior study could not assess the critical question relevant to the predictions of basic emotion theory, namely, whether basic emotions have consistent and specific correlates at the level of individual brain structures. Similarly, Phan et al. (2002) did not specifically assess whether each basic emotion could be discriminated from each of the other emotions on the basis of regional activations. Their metaanalysis focused on determining which particular brain regions were more consistently associated with one particular emotion than other emotions, and it did not assess the discriminability of basic emotions at any level. In addition to the methodological advantages associated with the current ALE meta-analysis, our review examined the considerably enlarged literature (50\% more studies published subsequent to the most recent meta-analytic review; Murphy et al., 2003) that has resulted from the recent increase in the number of neuroimaging studies examining the neural correlates of emotion. Although the majority of studies have explored the neural correlates of basic emotions using facial emotion stimuli, more recent studies have increasingly adopted a broader range of stimuli and methods. Together, these two considerations motivated a reexamination of whether the existing neuroimaging evidence supports the basic emotion view.

To address whether there are differentiable patterns of neural activity specific to each basic emotion we conducted two primary types of analysis, which can be characterized as assessing the consistency and discriminability of emotion-related activations, respectively. Consistency analyses determined the brain regions whose activity was most consistently and strongly associated with each of the individual basic emotions. Basic emotion theories predict that there should be characteristic regional brain activations that are reliably associated with the experience of each basic emotion. These neural correlates are also predicted to be discrete or discriminable, in the sense that each basic emotion is associated with some unique regional activations not shared by the other emotions. To test this prediction, we contrasted the activations associated with each basic emotion, assessing whether patterns of regional brain activation can discriminate between different basic emotions. The degree of support or lack of support for basic emotion theories was assessed primarily on the extent to which basic emotions were associated with consistent and discriminable regional activations.

In addition, we anticipated that the regions identified in the consistency and discriminability analyses would overlap to some degree on the basis of the view that some subset of the characteristic neural activations for each emotion also would comprise the activations that differentiated that emotion from others. Finally, we also predicted that the characteristic patterns of regional brain activity associated with basic emotions as observed with neuroimaging should converge with the regions identified using other neuroscience methods such as neuropsychological studies. For example, because neuropsychological lesion studies in humans have demonstrated that the amygdala 
is a structure critically implicated in the experience of fear and the acquisition of fear responses, one would predict that the amygdala should be among the brain regions characteristic of the basic emotion fear in our meta-analysis (Adolphs, Tranel, Damasio, \& Damasio, 1994).

\section{METHODS}

\section{Scope of the Review}

To investigate patterns of neural activation associated with discrete basic emotions, we examined neuroimaging studies that included either an explicit emotional elicitation task (e.g., mood induction), emotionally arousing stimuli (e.g., emotional pictures), or emotional facial expressions. Like Murphy et al. (2003), the current analysis considered studies that addressed any aspect of an emotional experience: expression, perception, interpretation, or subjective experience. Consequently, our meta-analysis examined neural activations across multiple studies that recruited a variety of different emotion-related processes. We elected to include all such studies rather than focus on studies using a particular methodology such as emotion induction because we were specifically interested in identifying the "core" neural patterns associated with basic emotions, reflected in the overlap of activations across different aspects of emotional experience.

Studies were selected based on a set of seven criteria that were adapted from inclusion criteria used in previous meta-analyses (e.g., Murphy et al., 2003; Phan et al., 2002). First, only studies conducted using $\mathrm{H}_{2}{ }^{15} \mathrm{O}$ PET and fMRI were considered. Second, coordinates needed to be reported in standard stereotactic space (either MNI or Talairach). Third, studies must have reported whole-brain analyses (we excluded those studies reporting only ROI analyses) to ensure that all regions in the brain were represented equivalently. Fourth, activation contrasts representing main effects of specific emotions relative to a baseline condition were required (e.g., viewing happy faces $>$ viewing neutral faces) so that the activations associated with each emotion could be analyzed independently of any other emotion. This criterion also reduced the influence of stimulus type on the reported effects because effective control stimuli were well matched on all elements except for emotional arousal. Fifth, the main effects reported in a study were required to include at least one basic emotion state (happiness, sadness, anger, fear, or disgust). Sixth, studies had to report activations (deactivations were not included in the analysis because the nature of the analysis technique did not afford differentiation of activations from deactivations). Seventh, only data from healthy individuals were included (studies of clinical patient groups were not considered).

Over 1,000 potential studies were identified by a search of electronic databases (PsychInfo, Medline, Web of Science ISI), Google Scholar, previous meta-analyses (Murphy et al., 2003; Phan et al., 2002), and relevant peer-reviewed journals. Eighty-three neuroimaging studies (PET and fMRI) published from 1993 to 2008 were selected for the analysis (for a summary, see Table 1). The current analysis included 30 studies (approximately 100\% more than Phan et al., 2002 and 50\% more than Murphy et al., 2003) published after the studies included in the most recent metaanalysis (Murphy et al., 2003). Studies included in the ALE meta-analysis are preceded in the References section by an asterisk.

\section{Activation Likelihood Estimation}

The current review used a recently developed neuroimaging meta-analysis method, ALE (Laird et al., 2005), which has considerable advantages over previously used labelbased methods where anatomic locations of activations are analyzed according to their corresponding neural structures. ALE is a quantitative method of assessing relationships between function (i.e., cognitive or emotional processes) and regional brain activations. In an ALE analysis, relevant neuroimaging studies are collected and analyzed in relation to specific experimental conditions (e.g., viewing a frightening scene vs. a neutral scene). Three-dimensional focus of activation is extracted in the form of Talairach or MNI coordinates corresponding to activation maxima for contrasts between experimental conditions. These sets of activation coordinates are then modeled as the centers of Gaussian probability distributions and are combined (summated) to create statistical whole-brain ALE maps. ALE maps preserve considerably more spatial information from the original maxima, relative to label-based methods, and substantially increase the spatial sensitivity of the analysis. The ALE maps are comprised of ALE statistics representing the likelihood that the voxel at that three-dimensional coordinate is active during the corresponding experimental condition across the entire set of studies analyzed (Laird et al., 2005). A further advantage of the ALE method is that these individual ALE maps can then be directly compared statistically, by contrasting the voxelwise differences between two ALE maps and comparing the resulting difference ALE map to a comparison null distribution generated by random permutation tests. To summarize the steps in the current ALE meta-analysis (for a complete description of the ALE method, see Laird et al., 2005), three-dimensional activation coordinates were extracted from the relevant studies for each basic emotion, converted to spatially smoothed activation foci volumes with a 10-mm FWHM Gaussian kernel, and pooled across studies to create statistical whole-brain maps using GingerALE 1.1 (Laird et al., 2005).

For consistency analyses, ALE statistic maps were calculated for each of the five basic emotions analyzed, and each ALE map was then compared with a corresponding comparison null distribution of the ALE statistic based on 5,000 random spatial permutations across the brain of an equivalent number of activation foci. Similarly, for discriminability analyses, ALE statistic maps were compared by 
Table 1. Studies Included in the Meta-analysis

\begin{tabular}{|c|c|c|c|c|c|c|}
\hline Study & Method & $n$ & Age & Experimental Paradigm & Modality & Emotion \\
\hline Aalto et al. (2002) & PET & $11 f$ & $18-44$ & Mood induction & V (Films) & $\mathrm{S}$ \\
\hline Aalto et al. (2005) & fMRI & $11 \mathrm{f}$ & 33.4 & Viewing emotional films & V (Films) & S \\
\hline Abel et al. (2003) & fMRI & $8 \mathrm{~m}$ & $\mathrm{~N} / \mathrm{A}$ & Viewing facial expressions & V (Faces) & $\mathrm{F}$ \\
\hline $\begin{array}{l}\text { Abler, Erk, Herwig, and } \\
\text { Walter (2007) }\end{array}$ & fMRI & $12 \mathrm{f}$ & 40.7 & Viewing emotional pictures & V (Pictures) & $\mathrm{D}$ \\
\hline $\begin{array}{l}\text { Ashwin, Baron-Cohen, } \\
\text { Wheelwright, O'Riordan, } \\
\text { and Bullmore (2007) }\end{array}$ & fMRI & $13 \mathrm{~m}$ & 25.6 & Viewing facial expressions & V (Faces) & $\mathrm{F}$ \\
\hline $\begin{array}{l}\text { Baker, Frith, and Dolan } \\
\text { (1997) }\end{array}$ & fMRI & $10 \mathrm{~m}$ & $18-35$ & Mood induction & V (Scripts/Music) & $\mathrm{H} \mathrm{S}$ \\
\hline Beauregard et al. (1998) & fMRI & $3 \mathrm{~m}, 4 \mathrm{f}$ & 45 & Viewing emotional films & V (Films) & $S$ \\
\hline Benuzzi et al. (2004) & fMRI & $7 \mathrm{~m}, 7 \mathrm{f}$ & $21-27$ & Viewing facial expressions & V (Faces) & $\mathrm{F}$ \\
\hline $\begin{array}{l}\text { Benuzzi, Lui, Duzzi, } \\
\text { Nichelli, and Porro } \\
\text { (2008) }\end{array}$ & fMRI & $15 \mathrm{f}$ & 23.5 & Viewing emotional films & V (Films) & $\mathrm{D}$ \\
\hline Blair et al. (1999) & PET & $13 \mathrm{~m}$ & 25 & Viewing facial expressions & V (Faces) & A \\
\hline Buchanan et al. (2000) & fMRI & $10 \mathrm{~m}$ & $22-40$ & Emotional prosody & A (Voices) & $\mathrm{H} \mathrm{S}$ \\
\hline Bystritsky et al. (2001) & fMRI & $3 \mathrm{~m}, 3 \mathrm{f}$ & 31.8 & Mood induction & A (Autobio Scripts) & $\mathrm{F}$ \\
\hline Damasio et al. (2000) & PET & 53 mix & $\mathrm{N} / \mathrm{A}$ & Induced mood & Autobio Recall & H S A F \\
\hline Dolan et al. (1996) & PET & $8 \mathrm{~m}$ & 23 & Viewing facial emotions & V (Faces) & $\mathrm{H}$ \\
\hline Dougherty et al. (1999) & PET & $8 \mathrm{~m}$ & 25 & Mood induction & A (Autobio Scripts) & A \\
\hline Eugene et al. (2003) & fMRI & $10 f$ & 24 & Viewing emotional films & V (Films) & S \\
\hline Fischer et al. (2005) & fMRI & $11 \mathrm{~m}, 11 \mathrm{f}$ & 74.1 & Viewing facial expressions & V (Faces) & A \\
\hline Fitzgerald et al. (2004) & fMRI & $7 \mathrm{~m}, 5 \mathrm{f}$ & 31.2 & Mood induction & Autobio Recall & $\mathrm{D}$ \\
\hline $\begin{array}{l}\text { Fitzgerald, Angstadt, } \\
\text { Jelsone, Nathan, and } \\
\text { Phan (2006) }\end{array}$ & fMRI & $10 \mathrm{~m}, 10 \mathrm{f}$ & 26 & Viewing facial expressions & V (Faces) & H S A F D \\
\hline George et al. (1995) & PET & $11 f$ & N/A & Induced mood & Autobio Recall/V (Faces) & S \\
\hline $\begin{array}{l}\text { George, Ketter, Parekh, } \\
\text { Herscovitch, and Post } \\
\text { (1996) }\end{array}$ & PET & $10 \mathrm{~m}, 10 \mathrm{f}$ & 35 & Induced mood & Autobio Recall/V (Faces) & $\mathrm{H} \mathrm{S}$ \\
\hline Goldin et al. (2005) & fMRI & $13 \mathrm{f}$ & 19.7 & Viewing emotional films & V (Films) & $\mathrm{H} \mathrm{S}$ \\
\hline Grandjean et al. (2005) & fMRI & $8 \mathrm{~m}, 7 \mathrm{f}$ & 24.4 & Emotional prosody & A (Pseudo Sentences) & A \\
\hline Grosbras and Paus (2005) & fMRI & $10 \mathrm{~m}, 10 \mathrm{f}$ & 28.6 & Viewing emotional films & V (Films) & A \\
\hline $\begin{array}{l}\text { Habel, Klein, Kellermann, } \\
\text { Shah, and Schneider } \\
\text { (2005) }\end{array}$ & fMRI & $26 \mathrm{~m}$ & 33.4 & Mood induction & V (Faces) & $\mathrm{H} \mathrm{S}$ \\
\hline Hadjikhani et al. (2003) & fMRI & $4 \mathrm{~m}, 3 \mathrm{f}$ & N/A & Viewing bodily expressions & V (Bodily Expressions) & $\mathrm{F}$ \\
\hline $\begin{array}{l}\text { Hariri, Mattay, Tessitore, } \\
\text { Fera, and Weinberger } \\
\text { (2003) }\end{array}$ & fMRI & $5 \mathrm{~m}, 6 \mathrm{f}$ & 32 & Viewing emotional pictures & V (Pictures) & $\mathrm{F}$ \\
\hline Harris and Fiske (2007) & fMRI & $10 \mathrm{mix}$ & N/A & Viewing emotional pictures & V (Pictures) & $\mathrm{D}$ \\
\hline Hutcherson et al. (2005) & fMRI & $28 \mathrm{f}$ & $18-21$ & Viewing emotional films & V (Films) & $\mathrm{H} \mathrm{S}$ \\
\hline Kesler/West et al. (2001) & fMRI & $11 \mathrm{~m}, 10 \mathrm{f}$ & 21.6 & Processing facial emotions & V (Faces) & $\mathrm{H} \mathrm{S} \mathrm{A} \mathrm{F}$ \\
\hline
\end{tabular}


Table 1. (continued)

\begin{tabular}{|c|c|c|c|c|c|c|}
\hline Study & Method & $n$ & Age & Experimental Paradigm & Modality & Emotion \\
\hline $\begin{array}{l}\text { Killgore and Yurgelun-Todd } \\
\text { (2004) }\end{array}$ & fMRI & $12 \mathrm{f}$ & 23.7 & Viewing facial expressions & V (Faces) & $\mathrm{H} \mathrm{S}$ \\
\hline $\begin{array}{l}\text { Kilts, Egan, Gideon, Ely, } \\
\text { and Hoffman (2003) }\end{array}$ & fMRI & $9 \mathrm{~m}, 4 \mathrm{f}$ & 24.5 & Viewing facial expressions & V (Faces) & $\mathrm{H} \mathrm{A}$ \\
\hline Kimbrell et al. (1999) & PET & $10 \mathrm{~m}, 8 \mathrm{f}$ & $31.2,34.7$ & Induced mood & Autobio Recall & $\mathrm{F}$ \\
\hline $\begin{array}{l}\text { Lane, Reiman, Ahern, } \\
\text { Schwartz, and } \\
\text { Davidson (1997) }\end{array}$ & PET & $12 f$ & 23.3 & Induced mood & V (Film)/Recall & H S D \\
\hline Lange et al. (2003) & fMRI & $9 \mathrm{~m}$ & 29 & Viewing facial expressions & V (Faces) & $\mathrm{F}$ \\
\hline Lemche et al. (2007) & fMRI & $5 \mathrm{f}, 7 \mathrm{~m}$ & 27.3 & Viewing facial expressions & V (Faces) & $\mathrm{H} \mathrm{S}$ \\
\hline $\begin{array}{l}\text { Lennox, Jacob, Calder, } \\
\text { Lupson, and Bullmore } \\
\text { (2004) }\end{array}$ & fMRI & $6 \mathrm{~m}, 6 \mathrm{f}$ & 32.6 & Viewing facial expressions & V (Faces) & $\mathrm{H} \mathrm{S}$ \\
\hline Liddell et al. (2005) & fMRI & $11 \mathrm{~m}, 11 \mathrm{f}$ & 32 & Viewing facial expressions & V (Faces) & $\mathrm{F}$ \\
\hline Liotti et al. (2000) & PET & $8 f$ & N/A & Mood induction & V (Autobio Scripts) & S \\
\hline Mayberg et al. (1999) & PET & $8 f$ & 36 & Mood induction & V (Autobio Scripts) & S \\
\hline Michalopoulou et al. (2008) & fMRI & $5 \mathrm{~m}, 4 \mathrm{f}$ & 32 & Viewing facial expressions & V (Faces) & $\mathrm{F}$ \\
\hline $\begin{array}{l}\text { Mitterschiffthaler, Fu, } \\
\text { Dalton, Andrew, and } \\
\text { Williams (2007) }\end{array}$ & fMRI & $8 \mathrm{~m}, 8 \mathrm{f}$ & 30.8 & Mood induction & A (Music) & $\mathrm{H} \mathrm{S}$ \\
\hline Moll et al. (2005) & fMRI & $7 \mathrm{~m}, 6 \mathrm{f}$ & 22.5 & Mood induction & V (Statements) & $\mathrm{D}$ \\
\hline Morris et al. (1998) & PET & $4 \mathrm{~m}, 1 \mathrm{f}$ & 42.8 & Viewing facial expressions & V (Faces) & $\mathrm{H} \mathrm{F}$ \\
\hline Ottowitz et al. (2004) & fMRI & $8 f$ & $18-30$ & Mood induction & V (Sentences) & $\mathrm{S}$ \\
\hline Paradiso et al. (1997) & PET & $2 \mathrm{~m}, 6 \mathrm{f}$ & 62.6 & Viewing emotional films & V (Film Clips) & H D \\
\hline $\begin{array}{l}\text { Paradiso, Robinson, Boles } \\
\text { Ponto, Watkins, and } \\
\text { Hichwa (2003) }\end{array}$ & fMRI & $9 \mathrm{~m}, 8 \mathrm{f}$ & 65 & Mood induction & V (Faces/Pictures) & $\mathrm{S}$ \\
\hline $\begin{array}{l}\text { Pardo, Pardo, and Raichle } \\
\text { (1993) }\end{array}$ & PET & $3 \mathrm{f}$ & 24 & Mood induction & Imagery & $\mathrm{S}$ \\
\hline Pelletier et al. (2003) & fMRI & $5 \mathrm{~m}, 4 \mathrm{f}$ & 33 & Mood induction & V (Autobio Recall) & $\mathrm{H} \mathrm{S}$ \\
\hline Phillips et al. (1997) & fMRI & $2 \mathrm{~m}, 5 \mathrm{f}$ & 27 & Viewing facial expressions & V (Faces) & F D \\
\hline $\begin{array}{l}\text { Phillips, Bullmore, et al. } \\
\text { (1998) }\end{array}$ & fMRI & $7 \mathrm{~m}, 1 \mathrm{f}$ & 32 & Viewing facial expressions & V (Faces) & $\mathrm{H} \mathrm{S}$ \\
\hline $\begin{array}{l}\text { Phillips, Young, et al. } \\
\text { (1998) }\end{array}$ & fMRI & $6 \mathrm{~m}$ & 37 & Vocal expressions & V (Faces)/A (Vocal) & F D \\
\hline Phillips et al. (1999) & fMRI & $5 \operatorname{mix}$ & 30 & Viewing facial expressions & V (Faces) & A F D \\
\hline Phillips et al. (2000) & fMRI & $7 \mathrm{~m}, 7 \mathrm{f}$ & 31 & Viewing emotional pictures & V (Pictures) & $\mathrm{D}$ \\
\hline Phillips et al. (2004) & fMRI & $5 \mathrm{~m}, 5 \mathrm{f}$ & 29.5 & Viewing facial expressions & V (Faces) & F D \\
\hline $\begin{array}{l}\text { Pietrini, Guazzelli, Basso, } \\
\text { Jaffe, and Grafman } \\
\text { (2000) }\end{array}$ & PET & $8 \mathrm{~m}, 7 \mathrm{f}$ & 22 & Mood induction & Imagery & A \\
\hline Pine et al. (2001) & fMRI & $10 \mathrm{~m}, 10 \mathrm{f}$ & $13.9,28.5$ & Visual masking paradigm & V (Faces) & $\mathrm{H} \mathrm{F}$ \\
\hline Salloum et al. (2007) & fMRI & $11 \mathrm{~m}$ & 36 & Viewing facial expressions & V (Faces) & H S A F D \\
\hline Sambataro et al. (2006) & fMRI & $11 \mathrm{~m}, 13 \mathrm{f}$ & 26.8 & Viewing facial expressions & V (Faces) & $\mathrm{D}$ \\
\hline
\end{tabular}


Table 1. (continued)

\begin{tabular}{|c|c|c|c|c|c|c|}
\hline Study & Method & $n$ & Age & Experimental Paradigm & Modality & Emotion \\
\hline $\begin{array}{l}\text { Sato, Kochiyama, } \\
\text { Yoshikawa, Naito, } \\
\text { and Matsamura (2004) }\end{array}$ & fMRI & $10 \mathrm{~m}, 12 \mathrm{f}$ & 26.5 & Viewing facial expressions & V (Dynamic Faces) & $\mathrm{H} \mathrm{F}$ \\
\hline $\begin{array}{l}\text { Schafer, Schienle, and } \\
\text { Vaitl (2005) }\end{array}$ & fMRI & $20 \mathrm{~m}, 20 \mathrm{f}$ & 23.93 & Viewing emotional pictures & V (Pictures) & $\mathrm{F}$ \\
\hline Schienle et al. (2002) & fMRI & $12 f$ & 26.3 & Viewing emotional pictures & V (Pictures) & F D \\
\hline $\begin{array}{l}\text { Schienle, Schäfer, Walter, } \\
\text { Stark, and Vaitl (2005) }\end{array}$ & fMRI & $63 f$ & 27.3 & Viewing emotional pictures & V (Pictures) & $\mathrm{D}$ \\
\hline Schienle et al. (2006) & fMRI & $12 \mathrm{f}$ & $19-41$ & Viewing emotional pictures & V (Pictures) & F D \\
\hline Shapira et al. (2003) & fMRI & $3 \mathrm{~m}, 5 \mathrm{f}$ & 38 & Viewing emotional pictures & V (Pictures) & $\mathrm{D}$ \\
\hline $\begin{array}{l}\text { Sprengelmeyer, Rausch, } \\
\text { Eysel, and Przuntek } \\
\text { (1998) }\end{array}$ & fMRI & $2 \mathrm{~m}, 4 \mathrm{f}$ & 23.5 & $\begin{array}{l}\text { Recognition of facial } \\
\text { expressions }\end{array}$ & V (Faces) & A F D \\
\hline Stark et al. (2003) & fMRI & $4 \mathrm{~m}, 11 \mathrm{f}$ & 29.1 & Viewing emotional films & V (Pictures) & F D \\
\hline Stark et al. (2005) & fMRI & $6 \mathrm{~m}$ & $\mathrm{~N} / \mathrm{A}$ & Viewing emotional pictures & V (Films) & F D \\
\hline Stark et al. (2007) & fMRI & $34 \mathrm{~m}, 32 \mathrm{f}$ & 24.7 & Viewing emotional pictures & V (Pictures) & F D \\
\hline Takahashi et al. (2008) & fMRI & $8 \mathrm{~m}, 8 \mathrm{f}$ & 21.5 & Mood induction & V (Sentences) & $\mathrm{H}$ \\
\hline $\begin{array}{l}\text { Thielscher and Pessoa } \\
\text { (2007) }\end{array}$ & fMRI & $10 \mathrm{~m}, 15 \mathrm{f}$ & 23 & Viewing facial expressions & V (Faces) & F D \\
\hline $\begin{array}{l}\text { Vuilleumier and Pourtois } \\
\text { (2007) }\end{array}$ & fMRI & $12 \operatorname{mix}$ & N/A & Viewing facial expressions & V (Faces) & $\mathrm{F}$ \\
\hline $\begin{array}{l}\text { Wang, McCarthy, Song, } \\
\text { and LaBar (2005) }\end{array}$ & fMRI & $5 \mathrm{~m}, 7 \mathrm{f}$ & 25.9 & Visual oddball task & V (Pictures) & S \\
\hline Whalen et al. (1998) & fMRI & $4 \mathrm{~m}, 4 \mathrm{f}$ & 25 & Viewing facial expressions & V (Faces) & A F \\
\hline Wicker et al. (2003) & fMRI & $14 \mathrm{~m}$ & $\mathrm{~N} / \mathrm{A}$ & Mood induction & $\mathrm{O}$ & $\mathrm{D}$ \\
\hline Williams et al. (2001) & fMRI & $11 \mathrm{~m}$ & 30 & Viewing facial expressions & V (Faces) & A \\
\hline Williams et al. (2004) & fMRI & $15 \mathrm{~m}, 7 \mathrm{f}$ & 27.5 & Viewing facial expressions & V (Faces) & $\mathrm{F}$ \\
\hline Williams et al. (2005) & fMRI & $5 \mathrm{~m}, 8 \mathrm{f}$ & 24 & Viewing facial expressions & V (Faces) & A F D \\
\hline $\begin{array}{l}\text { Winston, Vuilleumier, } \\
\text { and Dolan (2003) }\end{array}$ & fMRI & $6 \mathrm{~m}, 8 \mathrm{f}$ & 30 & Viewing facial expressions & $\mathrm{V}$ (Faces) & $\mathrm{F}$ \\
\hline $\begin{array}{l}\text { Wright, He, Shapira, } \\
\text { Goodman, and Liu } \\
\text { (2004) }\end{array}$ & fMRI & $4 \mathrm{~m}, 4 \mathrm{f}$ & $20-26$ & Viewing emotional pictures & V (Pictures) & F D \\
\hline
\end{tabular}

Characteristics of all studies included in the meta-analysis. Abbreviations for stimulus modality: $\mathrm{V}=$ visual; $\mathrm{A}=$ auditory; $\mathrm{O}=$ olfactory; for emotion category: $\mathrm{H}$ = happiness; $\mathrm{S}=$ sadness; $\mathrm{A}=$ anger; $\mathrm{F}=$ fear; $\mathrm{D}=$ disgust; experimental paradigm: Autobio = autobiographical.

contrasting the difference maps calculated from each pairwise contrast between individual emotion ALE maps (e.g., fear ALE map minus anger ALE map) across all basic emotions with a corresponding random null distribution. This null distribution was calculated, first, by generating 5,000 individual pairs of ALE maps, using the same permutation method as was used to compute individual ALE maps; second, by calculating a difference map for each pair; and third, by comparing the observed difference ALE map between the emotion pair with this null distribution. All thresholded ALE maps were corrected for multiple com- parisons using the false discovery rate algorithm $(q=.05)$ and were overlaid on a canonical single-subject anatomical T1 brain template from the SPM5 image library. Only significant clusters that exceeded $100 \mathrm{~mm}^{3}$ were reported.

In summary, the ALE meta-analysis was comprised of consistency analyses and discriminability analyses. Consistency analyses identified the regional brain activations regions most consistently associated with each basic emotion. Discriminability analyses identified brain regions that were significantly differentially active when contrasting pairs of discrete emotions, thus addressing whether 
basic emotion states are discriminable based on regional activations.

\section{RESULTS}

\section{Activation Consistency Analyses}

Happiness

The ALE analysis of activation foci associated with happiness revealed nine significant clusters, with the largest $\left(4880 \mathrm{~mm}^{3}\right)$ located primarily in the right superior temporal gyrus (STG; Brodmann's area [BA] 22; see Figure 1 and Table 2). Figure 1 displays ALE activation maps overlaid on eight axial slices from a canonical T1 anatomical image, centered on $z=0$, with the highest slice selected at a level that captured the most superior activation(s) across all statistical maps in the meta-analysis. The same display criteria were applied to all figures.

\section{Sadness}

The ALE analysis of activation foci associated with sadness revealed 35 significant clusters, with the largest $\left(3120 \mathrm{~mm}^{3}\right)$ located primarily in the left medial frontal gyrus (medFG; see Figure 1 and Table 2).

\section{Anger}

The ALE analysis of activation foci associated with anger revealed 13 significant clusters, with the largest $\left(2408 \mathrm{~mm}^{3}\right)$

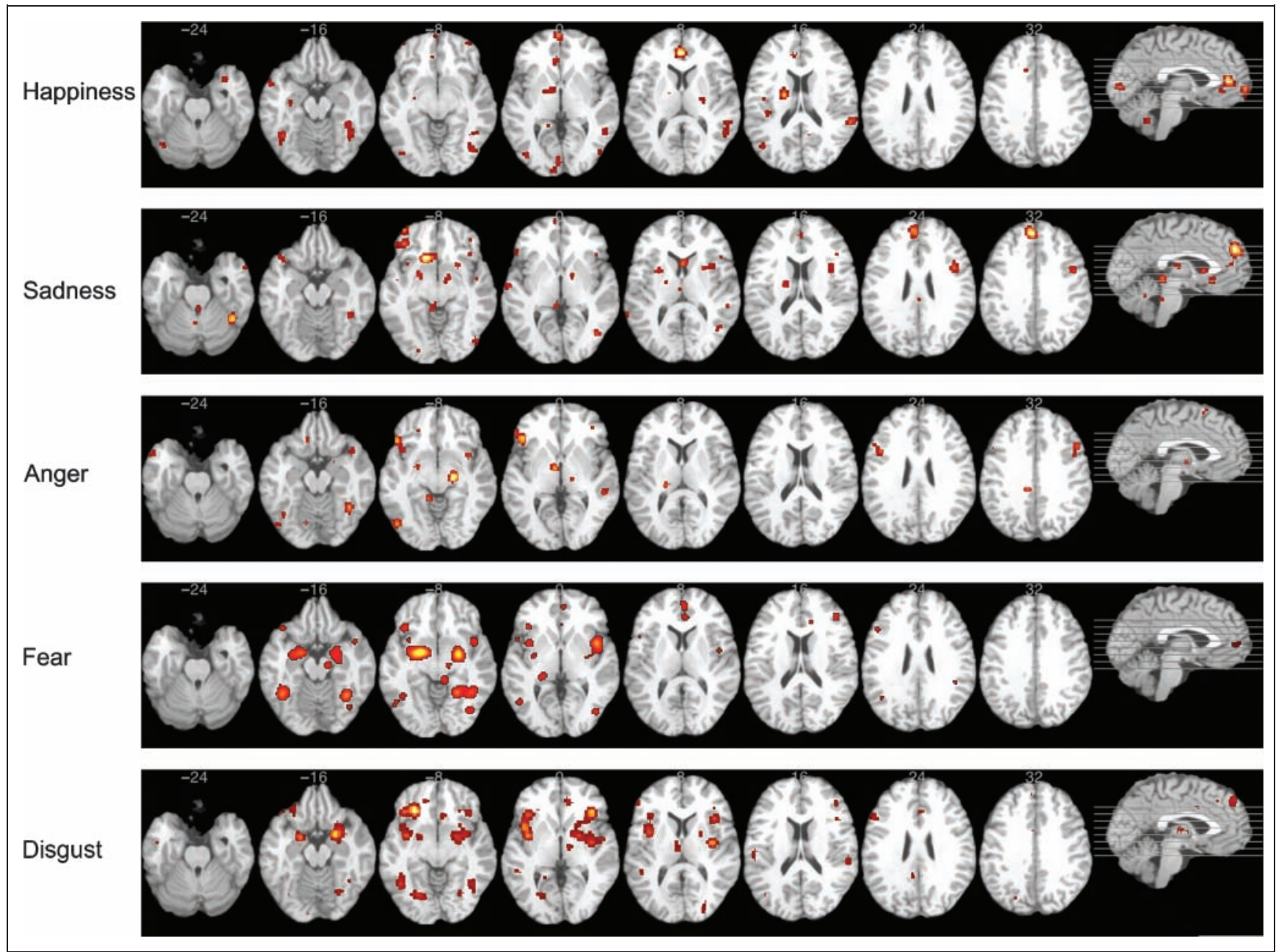

Figure 1. Activation likelihood maps representing regional activity consistently associated with each basic emotion state. Statistical map of significant ALE clusters associated with happiness, sadness, anger, fear, and disgust. The horizontal lines overlaid on the sagittal image (at far right) show the locations of the corresponding axial slices. All figures display slices in neurological convention, where the left side in the image corresponds to the left side of the image. ALE values are indicated by red-yellow color gradient clusters overlaid on a canonical structural image from SPM5. Rather than representing magnitude of activation, the color gradient represents the degree of overlap (i.e., activation likelihood or consistency) among the activation coordinates across studies that contributed to the analysis. The most prominent clusters associated with happiness are located in right STG (BA 22) and left ACC (BA 24). The most prominent clusters associated with sadness are located in left caudate head and left medFG (BA 9) and right IFG (BA 9). The most prominent clusters associated with anger are located in left IFG (BA 47) and right parahippocampal gyrus (BA 35). The most prominent clusters associated with fear are located in bilateral amygdala, right cerebellum, and right insula. The most prominent clusters associated with disgust are located in bilateral insula (BA 47). 
Table 2. ALE Activation Clusters Consistently Associated with Each Basic Emotion State

\begin{tabular}{|c|c|c|c|c|}
\hline \multicolumn{3}{|c|}{ Activation Focus } & \multirow[b]{2}{*}{ Region $\left(>100 \mathrm{~mm}^{3}\right)$} & \multirow[b]{2}{*}{ Size } \\
\hline$x$ & $y$ & $z$ & & \\
\hline \multicolumn{5}{|c|}{ Happiness } \\
\hline 47.8 & -52.9 & -0.6 & R STG (BA 22) ${ }^{\mathrm{a}}$ & 4880 \\
\hline-1.9 & 42.3 & 4.2 & $\mathrm{~L}$ ACC (BA 24) $)^{\mathrm{a}}$ & 3232 \\
\hline-40.2 & -61.9 & -18.4 & $\mathrm{~L}_{\text {cerebellum }}{ }^{\mathrm{a}}$ & 1176 \\
\hline-18.3 & -9.3 & 16.6 & L thalamus & 960 \\
\hline-4.2 & -91.5 & 1.7 & L lingual gyrus & 888 \\
\hline-12.2 & -5.7 & 1.5 & L thalamus & 82 \\
\hline-39.1 & -78.8 & -2.8 & L Inf Occ gyrus ${ }^{\mathrm{a}}$ & 528 \\
\hline-36.9 & -31.0 & 18.0 & $\mathrm{~L}$ insula ${ }^{\mathrm{a}}$ & 288 \\
\hline 24.7 & -16.0 & 7.8 & $\mathrm{R}$ basal ganglia (Put) ${ }^{\mathrm{a}}$ & 200 \\
\hline \multicolumn{5}{|l|}{ Anger } \\
\hline-44.4 & 22.5 & -3.4 & L IFG $(\mathrm{BA} 47)^{\mathrm{a}}$ & 2408 \\
\hline 18.6 & -19.4 & -8.1 & R PHG & 154 \\
\hline-43.6 & -70.7 & -11.3 & L fusiform gyrus ${ }^{\mathrm{a}}$ & 1480 \\
\hline 39.1 & 8.0 & -14.5 & R IFG (BA 13) & 1008 \\
\hline 37.3 & -54.5 & -15.7 & $\mathrm{R}_{\text {cerebellum }}{ }^{\mathrm{a}}$ & 1000 \\
\hline 48.1 & 13.1 & 30.0 & R MFG (BA 9) & 928 \\
\hline-45.2 & 11.5 & 25.9 & L IFG (BA 9) ${ }^{\mathrm{a}}$ & 90 \\
\hline-6.1 & -8.5 & 1.0 & L thalamus ${ }^{\mathrm{a}}$ & 568 \\
\hline-50.8 & 7.7 & -22.4 & L STG & 46 \\
\hline-22.7 & -7.3 & -8.0 & L amygdala & 128 \\
\hline 4.6 & 45.0 & -4.0 & $\mathrm{R}$ ACC $(\mathrm{BA} 32)^{\mathrm{a}}$ & 128 \\
\hline-11.0 & 24.0 & -16.2 & L medFG (BA 25) & 120 \\
\hline 12.0 & -23.0 & 64.0 & $\mathrm{R}$ medFG $(\mathrm{BA} 6)^{\mathrm{a}}$ & 112 \\
\hline \multicolumn{5}{|l|}{ Fear } \\
\hline-22.7 & -5.9 & -9.0 & $\mathrm{~L}$ amygdala ${ }^{\mathrm{a}}$ & 5616 \\
\hline 22.7 & -10.6 & -11.1 & $\mathrm{R}$ amygdala ${ }^{\mathrm{a}}$ & 4248 \\
\hline 32.6 & -53.3 & -9.9 & $\mathrm{R}_{\text {cerebellum }}{ }^{\mathrm{a}}$ & 4176 \\
\hline 42.7 & 2.7 & -1.5 & $\mathrm{R}$ insula (BA 13) & 289 \\
\hline-40.1 & -55.7 & -13.8 & $\mathrm{~L}$ fusiform gyrus ${ }^{\mathrm{a}}$ & 2848 \\
\hline-37.5 & 22.6 & -7.4 & $\mathrm{~L}$ IFG $(\mathrm{BA} 47)^{\mathrm{a}}$ & 1320 \\
\hline 4.0 & 43.6 & 4.8 & R ACC (BA 32) & 1168 \\
\hline 38.6 & -73.0 & -7.4 & R Inf Occ gyrus ${ }^{a}$ & 1072 \\
\hline 37.7 & 10.4 & 19.9 & $\mathrm{R}$ insula $(\mathrm{BA} 13)^{\mathrm{a}}$ & 368 \\
\hline 42.5 & -40.2 & 20.6 & $\mathrm{R}$ Insula (BA 13) & 320 \\
\hline 13.0 & 29.7 & 13.7 & $\mathrm{R}$ ACC $(\mathrm{BA} 32)^{\mathrm{a}}$ & 176 \\
\hline \multicolumn{5}{|c|}{ Sadness } \\
\hline-3.5 & 46.8 & 27.1 & $\mathrm{~L}$ medFG $(\mathrm{BA} 9)^{\mathrm{a}}$ & 3120 \\
\hline 39.3 & 6.4 & 20.9 & R IFG (BA 9) & 2576 \\
\hline-9.8 & 17.7 & -8.3 & L caudate head ${ }^{\mathrm{a}}$ & 1960 \\
\hline
\end{tabular}

Table 2. (continued)

\begin{tabular}{|c|c|c|c|c|}
\hline \multicolumn{3}{|c|}{ Activation Focus } & \multirow[b]{2}{*}{ Region $\left(>100 \mathrm{~mm}^{3}\right)$} & \multirow[b]{2}{*}{ Size } \\
\hline$x$ & $y$ & $z$ & & \\
\hline-38.3 & 39.9 & -7.6 & L MFG (BA 10) ${ }^{\mathrm{a}}$ & 1632 \\
\hline 40.0 & -51.1 & -21.5 & $\mathrm{R}_{\text {cerebellum }}{ }^{\mathrm{a}}$ & 1344 \\
\hline 43.4 & -66.3 & 4.2 & R ITG & 880 \\
\hline-4.6 & -38.8 & -5.2 & L cerebellum $^{\mathrm{a}}$ & 840 \\
\hline 1.8 & 11.6 & 6.2 & $\mathrm{R}$ caudate head & 816 \\
\hline-16.5 & -11.6 & 13.9 & L thalamus ${ }^{\mathrm{a}}$ & 808 \\
\hline 13.0 & -5.3 & -6.2 & $\mathrm{R} P H G^{\mathrm{a}}$ & 784 \\
\hline-36.5 & 13.6 & -13.5 & L IFG (BA 13) & 632 \\
\hline 2.9 & 7.8 & 62.0 & $\mathrm{R} \mathrm{SFG}^{\mathrm{a}}$ & 512 \\
\hline-47.2 & -6.6 & 41.1 & L precentral gyrus & 496 \\
\hline 44.4 & -78.4 & -10.4 & R middle Occ gyrus & 456 \\
\hline-20.4 & -1.2 & -7.4 & L basal ganglia (GP) & 408 \\
\hline-59.2 & -14.7 & -0.7 & L STG & 400 \\
\hline 39.6 & 21.5 & -4.2 & L IFG (BA 47) & 352 \\
\hline-26.3 & 2.7 & 9.1 & L basal ganglia (Put) & 336 \\
\hline 44.2 & 21.1 & 12.2 & R IFG (BA 45) & 272 \\
\hline 23.5 & 8.6 & -6.9 & R basal ganglia (Put) & 208 \\
\hline-49.9 & 25.2 & 0.5 & L IFG (BA 45) & 208 \\
\hline 33.1 & -21.9 & 19.2 & $\mathrm{R}$ insula (BA 13) & 128 \\
\hline \multicolumn{5}{|l|}{ Disgust } \\
\hline 30.4 & 4.4 & -3.5 & R IFG (BA 47/Insula) ${ }^{a}$ & 14208 \\
\hline-26 & 28 & -10 & L IFG (BA 47/Insula) ${ }^{\mathrm{a}}$ & 10720 \\
\hline-22.0 & -70.0 & -6.0 & L lingual gyrus ${ }^{\mathrm{a}}$ & 1800 \\
\hline-19.7 & -3.3 & -13.8 & L amygdala & 1352 \\
\hline-41.0 & -55.2 & -9.0 & L fusiform gyrus ${ }^{\mathrm{a}}$ & 1272 \\
\hline 39.8 & -58.2 & -9.2 & $\mathrm{R}$ fusiform gyrus & 1104 \\
\hline-1.6 & 43.6 & 39.7 & L medFG & 960 \\
\hline 26.7 & -67.3 & -12.3 & $\mathrm{R}_{\text {cerebellum }}{ }^{\mathrm{a}}$ & 680 \\
\hline-49.7 & 18.8 & 26.3 & R IFG (BA 9) & 672 \\
\hline-4.3 & -13.9 & 7.1 & $\mathrm{~L}$ thalamus & 512 \\
\hline-47.4 & -43.6 & 3.9 & L MTG & 472 \\
\hline 26.7 & -83.1 & 9.7 & R middle Occ gyrus & 408 \\
\hline 9.6 & 37.6 & -0.6 & R ACC & 384 \\
\hline 6.9 & 20.7 & -8.7 & R ACC (BA 32) & 288 \\
\hline-13.6 & 38.2 & -6.9 & L medFG (BA 10) & 264 \\
\hline-49.7 & 36.1 & 9.0 & L IFG (BA 46) & 200 \\
\hline
\end{tabular}

Each cluster greater than $400 \mathrm{~mm}^{3}$ is reported, along with the weighted central activation likelihood focus, the region corresponding to the highest ALE score within the cluster, and the total cluster size in $\mathrm{mm}^{3}$. Additional clusters of interest that surpassed a threshold of $100 \mathrm{~mm}^{3}$ are also reported. $\mathrm{L}$ and $\mathrm{R}$ indicate activations located in the left and right hemispheres, respectively. Inf = inferior; Occ = occipital; GP = globus pallidus; Put = putamen; PHG $=$ parahippocampal gyrus. BAs are provided to differentiate activations in larger regions that occur in multiple contrasts.

${ }^{a}$ Indicates regions overlapping with the reanalysis that involved only studies that used facial expressions. 
located primarily in the left inferior frontal gyrus (IFG; BA 47; see Figure 1 and Table 2).

\section{Fear}

The ALE analysis of activation foci associated with fear revealed 11 significant clusters, with the largest $\left(5616 \mathrm{~mm}^{3}\right)$ located primarily in the left amygdala (see Figure 1 and Table 2).

\section{Disgust}

The ALE analysis of activation foci associated with disgust revealed 16 significant clusters, with the largest $\left(14208 \mathrm{~mm}^{3}\right)$ located primarily in the right insula and right IFG (BA 47; see Figure 1 and Table 2).

\section{Activation Discriminability Analyses}

\section{Happiness-Sadness}

The ALE analysis of activation foci associated with happiness greater than sadness revealed four significant clusters, with the largest $\left(424 \mathrm{~mm}^{3}\right)$ located primarily in the right STG (see Figure 2 and Table 3). The ALE analysis of activation foci associated with sadness greater than happiness revealed 12 significant clusters, with the largest $\left(2536 \mathrm{~mm}^{3}\right)$ located primarily in the right middle temporal gyrus (MTG; BA 24; see Figure 2 and Table 3). For all contrast analysis figures, clusters displayed in the red gradient correspond to the emotion state that is being subtracted from in the contrast; clusters displayed in the blue gradient correspond to the emotion state that is being subtracted.

\section{Happiness-Anger}

The ALE analysis of activation foci associated with happiness greater than anger revealed six significant clusters, with the largest $\left(1032 \mathrm{~mm}^{3}\right)$ located primarily in the left rostral ACC (BA 32; see Figure 2 and Table 3). The ALE analysis of activation foci associated with anger greater than happiness revealed six significant clusters, with the largest $\left(1536 \mathrm{~mm}^{3}\right.$ ) located primarily in the IFG (BA 47; see Figure 2 and Table 3).

\section{Happiness-Fear}

The ALE analysis of activation foci associated with happiness greater than fear revealed six significant clusters, with the largest $\left(1592 \mathrm{~m}^{3}\right)$ located primarily in the right STG (BA 22; see Figure 2 and Table 3). The ALE analysis of activation foci associated with fear greater than happiness revealed 11 significant clusters, with the largest $\left(3192 \mathrm{~m}^{3}\right)$ located primarily in the left amygdala.

\section{Happiness-Disgust}

The ALE analysis of activation foci associated with happiness greater than disgust revealed four significant clusters, with the largest $\left(672 \mathrm{~mm}^{3}\right)$ located primarily in the left rostral ACC (BA 24; see Figure 2 and Table 3). The ALE analysis of activation foci associated with disgust versus happiness revealed 11 significant clusters, with the largest $\left(12008 \mathrm{~mm}^{3}\right)$ located primarily in the right putamen (see Figure 2 and Table 3).

\section{Sadness-Anger}

The ALE analysis of activation foci associated with sadness greater than anger revealed 18 significant clusters, with the largest $\left(2280 \mathrm{~mm}^{3}\right)$ located primarily in the left MFG (BA 9; see Figure 2 and Table 3 ). The ALE analysis of activation foci associated with anger greater than sadness revealed three significant clusters, with the largest $\left(608 \mathrm{~mm}^{3}\right)$ located primarily in the right parahippocampal gyrus (BA 35; see Figure 2 and Table 3).

\section{Sadness-Fear}

The ALE analysis of activation foci associated with sadness greater than fear revealed 14 significant clusters, with the largest $\left(20840 \mathrm{~mm}^{3}\right)$ located primarily in the left medFG (see Figure 2 and Table 3). The ALE analysis of activation foci associated with fear revealed six significant clusters, with the largest $\left(2632 \mathrm{~mm}^{3}\right)$ located primarily in the left amygdala (see Figure 2 and Table 3).

\section{Sadness-Disgust}

The ALE analysis of activation foci associated with sadness greater than disgust revealed 12 significant clusters, with the largest $\left(1584 \mathrm{~mm}^{3}\right)$ located primarily in the right IFG (BA 9; see Figure 2 and Table 3). The ALE analysis of activation foci associated with disgust greater than sadness revealed 10 significant clusters, with the largest $\left(6392 \mathrm{~mm}^{3}\right)$ located primarily in the left insula (see Figure 2 and Table 3).

\section{Anger-Fear}

The ALE analysis of activation foci associated with anger greater than fear revealed four significant clusters, with the largest $\left(4784 \mathrm{~mm}^{3}\right)$ located primarily in the left IFG (BA 47; see Figure 2 and Table 3). The ALE analysis of activation foci associated with fear greater than anger revealed 11 significant clusters, with the largest $\left(3688 \mathrm{~mm}^{3}\right)$ located primarily in the left putamen (see Figure 2 and Table 3). 

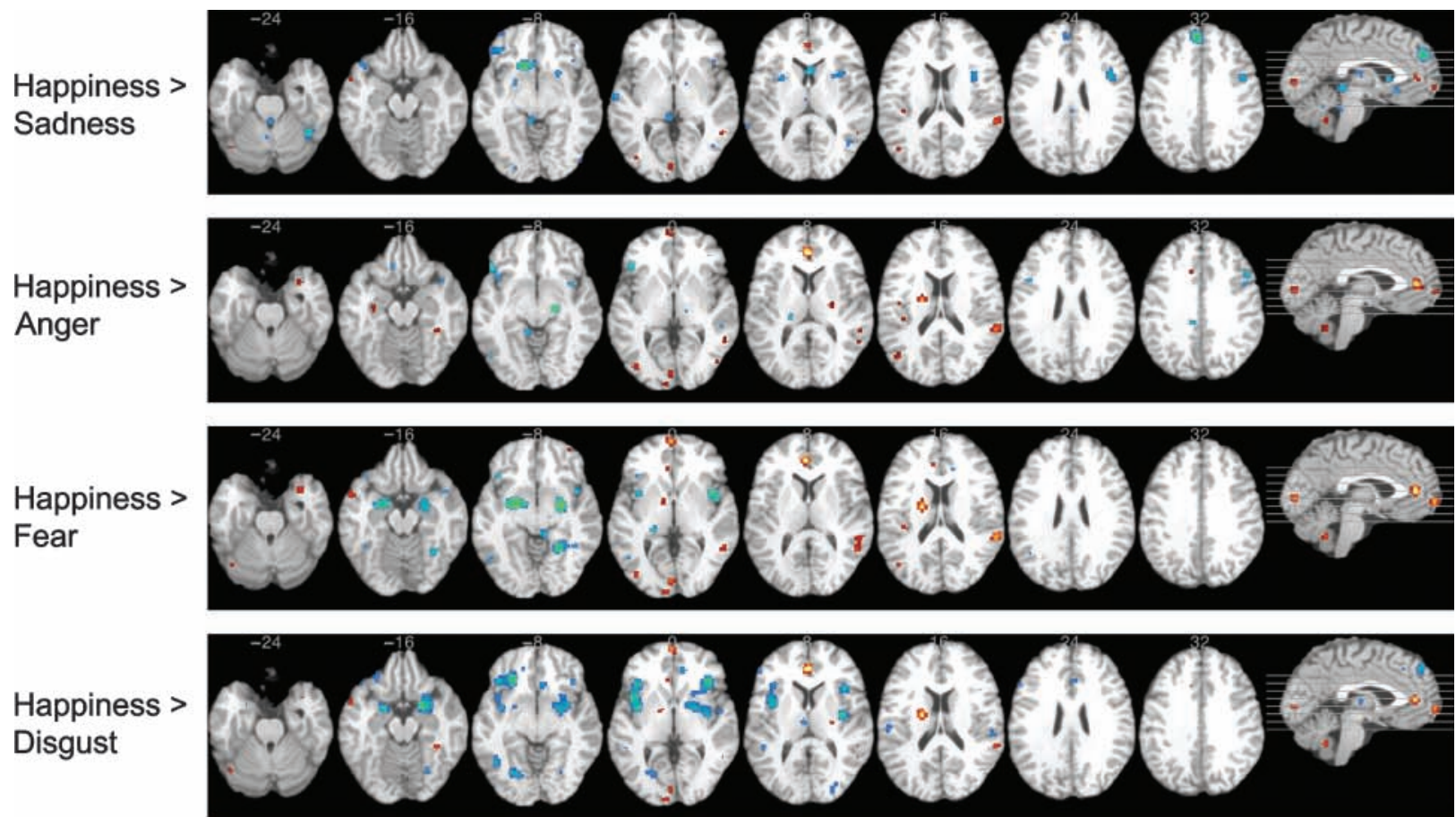

Sadness > Anger

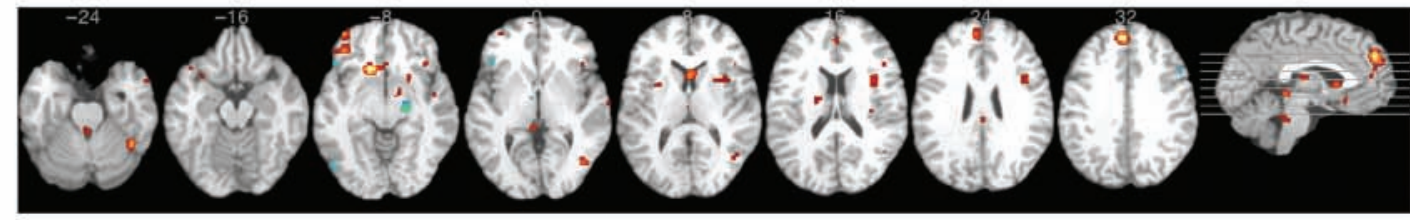

Sadness >

Fear

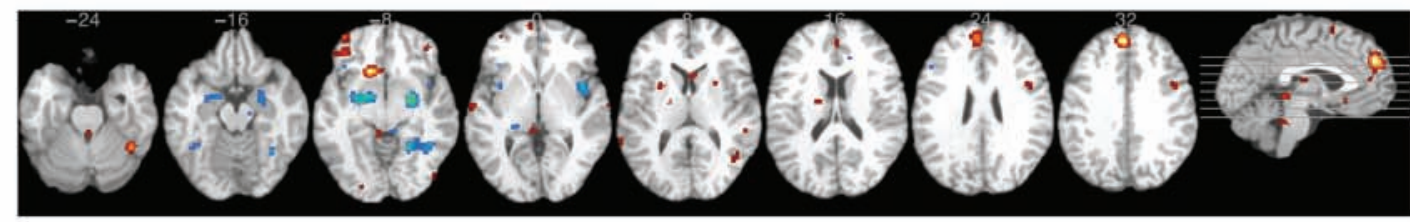

Sadness >

Disgust

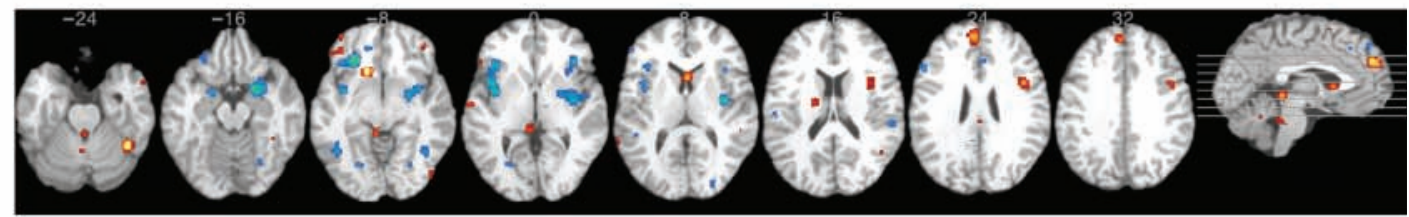

Anger >

Fear

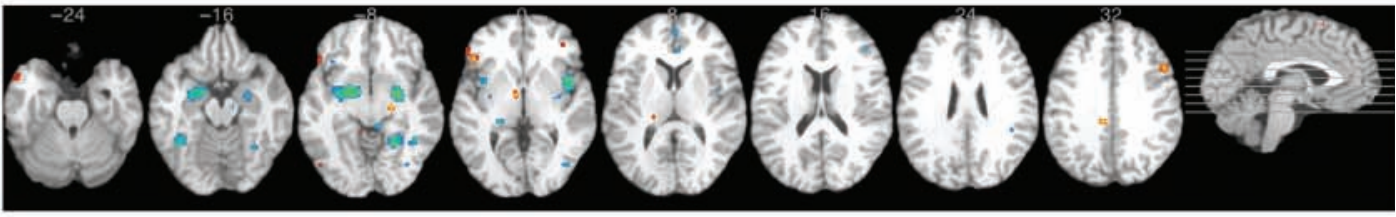

Anger >

Disgust

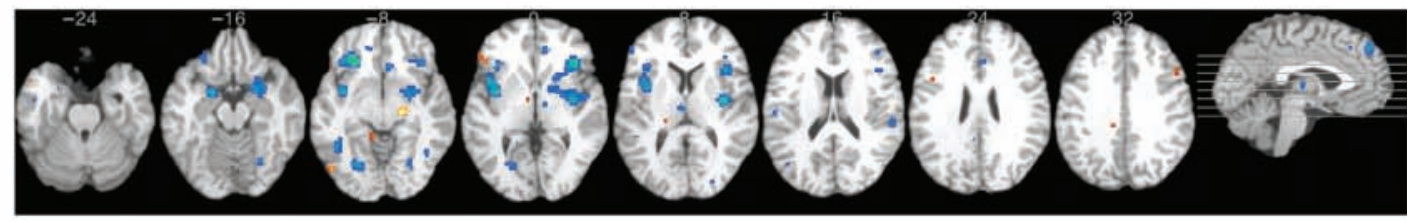

Fear >

Disgust

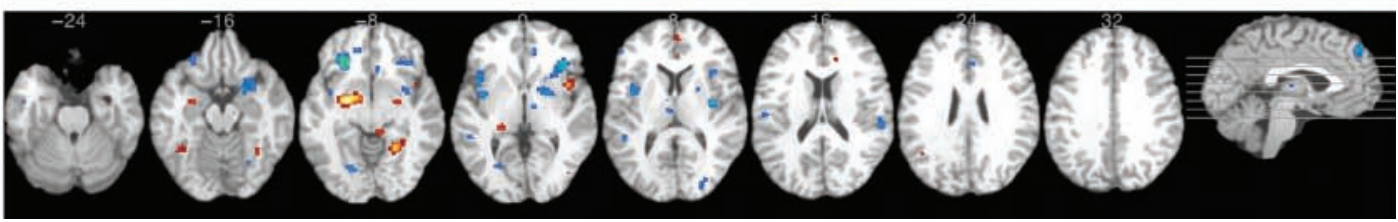




\section{Anger-Disgust}

The ALE analysis of activation foci associated with anger greater than disgust revealed four significant clusters, with the largest $\left(544 \mathrm{~mm}^{3}\right)$ located primarily in the left IFG (BA 47; see Figure 2 and Table 3). The ALE analysis of activation foci associated with disgust greater than anger revealed 15 significant clusters, with the largest $\left(10696 \mathrm{~mm}^{3}\right)$ located primarily in the right putamen (see Figure 2 and Table 3).

\section{Fear-Disgust}

The ALE analysis of activation foci associated with fear greater than disgust revealed nine significant clusters, with the largest $\left(2264 \mathrm{~mm}^{3}\right)$ located primarily in the left amygdala (see Figure 2 and Table 3). The ALE analysis of activation foci associated with disgust greater than fear revealed 12 significant clusters, with the largest $\left(2328 \mathrm{~mm}^{3}\right)$ located primarily in the right putamen (see Figure 2 and Table 3).

\section{Comparison with Previous Meta-analyses}

The current meta-analysis identified consistent and discriminable patterns of neural activation associated with each basic emotion state. To further investigate the differences between the current findings and the findings of previous meta-analyses, we examined whether these differences were the result of the inclusion of additional data and/or the use of a more sensitive meta-analytic method (ALE). Specifically, we compared our findings to those that would have been obtained were we to limit our data only to the studies included the previous meta-analyses. That is, we kept analysis method constant and varied the specific studies included to match the studies examined by Murphy et al. (2003). Phan et al. (2002) did not directly address the differentiability of emotion states in their analyses, and thus it was not necessary to reanalyze their data separately from that of Murphy et al. (2003).

Murphy et al. (2003) did not find that the neural correlates of happiness and sadness could be differentiated based on the distribution of activations across the eight spatial divisions of the brain they analyzed. In contrast, we found that the ALE method was able to discriminate between these two emotions, in addition to all pairwise emotion comparisons (see Table 4), using the same data set used by Murphy et al. Furthermore, the areas that differentiated basic emotion states when ALE was applied to the prior data set substantially overlapped corresponding regions in the current meta-analysis. For example, 7 of 10 pairwise contrasts between emotion states using the data set of Murphy et al. revealed clusters that matched at least one of the three largest clusters for the corresponding pairwise contrasts in the current meta-analysis.

In summary, we were able to differentiate between each of the basic emotions with the smaller data set, even in cases where this was not possible in the original study, which used a different meta-analysis method. In addition, there was notable overlap between the results of the ALE analysis using the Murphy et al. data set and the results of the current ALE meta-analysis. These results suggest that the greater sensitivity of the ALE method contributed an increased ability to discriminate between emotion states in the current meta-analysis. Furthermore, comparison of the results obtained with both data sets confirmed that the substantially larger number of studies we examined relative to previous studies also contributed significantly

Figure 2. Activation likelihood maps for pairwise emotion contrasts, representing regional activations discriminating between basic emotion states. Statistical maps of significant ALE clusters associated with all pairwise contrasts among emotion states. Clusters displayed in the red-yellow color gradient correspond to the emotion state that is being subtracted from in the contrast (i.e., the minuend; e.g., happiness); clusters displayed in the blue-green color gradient correspond to the emotion state that is being subtracted (i.e., the subtrahend; e.g., sadness). In the Happiness-Sadness contrast, the most prominent clusters associated with happiness are located in right STG (BA 22) and left ACC (BA 32). In the Happiness-Sadness contrast, the most prominent clusters associated with sadness are located in right MTG (BA 37) and left medFG (BA 9). In the Happiness-Anger contrast, the most prominent clusters associated with happiness are located in left ACC (BA 32) and right STG (BA 22). In the Happiness-Anger contrast, the most prominent clusters associated with anger are located in left IFG (BA 47) and right parahippocampal gyrus (BA 35). In the Happiness-Fear contrast, the most prominent clusters associated with happiness are located in right STG (BA 22) and left ACC (BA 32). In the Happiness-Fear contrast, the most prominent clusters associated with fear are located in bilateral amygdala. In the Happiness-Disgust contrast, the most prominent clusters associated with happiness are located in left ACC (BA 24) and left medFG (BA 10). In the Happiness-Disgust contrast, the most prominent clusters associated with disgust are located in bilateral amygdala. In the Sadness-Anger contrast, the most prominent clusters associated with sadness are located in left MFG (BA 9) and right insula (BA 13). In the Sadness-Anger contrast, the most prominent clusters associated with anger are located in the right parahippocampal gyrus (BA 35) and left IFG (BA 47). In the Sadness-Fear contrast, the most prominent clusters associated with sadness are located in left medFG (BA 9) and left caudate head. In the Sadness-Fear contrast, the most prominent clusters associated with fear are located in bilateral amygdala. In the Sadness-Disgust contrast, the most prominent clusters associated with sadness are located in right IFG (BA 9) and left MFG (BA 9). In the Sadness-Disgust contrast, the most prominent clusters associated with disgust are located in bilateral insula and right STG (BA 22). In the anger-fear contrast, the most prominent clusters associated with anger are located in left IFG (BA 47) and right MFG (BA 9). In the Anger-Fear contrast, the most prominent clusters associated with fear are located in left putamen and right insula (BA 13). In the Anger-Disgust contrast, the most prominent clusters associated with anger are located in left IFG (BA 47) and left fusiform gyrus (BA 19). In the Anger-Disgust contrast, the most prominent clusters associated with disgust are located in right putamen and left insula (BA 13). In the Fear-Disgust contrast, the most prominent clusters associated with fear are located in left amygdala and right parahippocampal gyrus (BA 19). In the Fear-Disgust contrast, the most prominent clusters associated with disgust are located in left putamen and right IFG (BA 47). 
Table 3. ALE Activation Clusters Differentiating Each Basic Emotion State

\begin{tabular}{|c|c|c|c|c|}
\hline \multicolumn{3}{|c|}{ Activation Focus } & \multirow[b]{2}{*}{ Region $\left(>100 \mathrm{~mm}^{3}\right)$} & \multirow[b]{2}{*}{ Size } \\
\hline$x$ & $y$ & $z$ & & \\
\hline \multicolumn{5}{|c|}{ Happiness-Sadness } \\
\hline \multicolumn{5}{|c|}{ Happiness > Sadness } \\
\hline 59.7 & -40.5 & 15.7 & $\mathrm{R} \mathrm{STG}^{\mathrm{a}}$ & 424 \\
\hline-0.4 & 39.3 & 6.7 & $\mathrm{~L}$ ACC $(\mathrm{BA} \mathrm{32})^{\mathrm{a}}$ & 344 \\
\hline-36.7 & -30.5 & 18.2 & L insula (BA 13) & 120 \\
\hline-0.7 & 57.2 & -3.2 & L medFG $(\mathrm{BA} 10)^{\mathrm{a}}$ & 112 \\
\hline \multicolumn{5}{|c|}{ Sadness > Happiness } \\
\hline 43.4 & -64.6 & 6.8 & R MTG & 2536 \\
\hline-4.2 & 46.9 & 30.5 & $\mathrm{~L}$ medFG $(\mathrm{BA} 9)^{\mathrm{a}}$ & 1976 \\
\hline-10.7 & 17.2 & -8.9 & L caudate head ${ }^{\mathrm{a}}$ & 1760 \\
\hline-1.7 & -20.9 & 10.7 & L thalamus ${ }^{\mathrm{a}}$ & 888 \\
\hline-63.5 & -47.4 & 7.0 & L MTG & 800 \\
\hline-21.1 & -0.6 & -7.8 & L basal ganglia & 624 \\
\hline 40.6 & 21.4 & -3.6 & R IFG (BA 47) & 528 \\
\hline 43.8 & 21.1 & 12.5 & R IFG (BA 45) & 464 \\
\hline-37.5 & 14.7 & -13.6 & L IFG (BA 47) & 464 \\
\hline 39.8 & 6.40 & 21.7 & R basal ganglia (Put) & 408 \\
\hline-26.8 & 3.20 & 9.0 & L basal ganglia (Put) & 272 \\
\hline 22.9 & 8.30 & -6.8 & R basal ganglia (Put) & 272 \\
\hline \multicolumn{5}{|c|}{ Happiness-Disgust } \\
\hline \multicolumn{5}{|c|}{ Happiness $>$ Disgust } \\
\hline 0.1 & 38 & 8.1 & L ACC (BA 24) & 672 \\
\hline-18.5 & -9.5 & 17.1 & $\mathrm{~L}$ thalamus & 624 \\
\hline-0.9 & 58.4 & -1.3 & $\mathrm{~L}$ medFG $(\mathrm{BA} 10)^{\mathrm{a}}$ & 456 \\
\hline-13.4 & -6.1 & 1.9 & L basal ganglia (GP) & 136 \\
\hline \multicolumn{5}{|c|}{ Disgust $>$ Happiness } \\
\hline 30.5 & 4.9 & -3.7 & $\mathrm{R}$ basal ganglia (Put) ${ }^{\mathrm{a}}$ & 12008 \\
\hline-34.7 & 14.7 & -3.2 & L IFG (BA 47/Insula) ${ }^{\mathrm{a}}$ & 9040 \\
\hline-22.2 & -70.9 & -6.2 & L lingual gyrus ${ }^{\mathrm{a}}$ & 1680 \\
\hline-20.1 & -2.6 & -14.7 & $\mathrm{~L}$ amygdala & 1184 \\
\hline-1.3 & 43.5 & 39.7 & L medFG (BA 8) & 904 \\
\hline-41.2 & -58.7 & -7.2 & L fusiform gyrus ${ }^{\mathrm{a}}$ & 520 \\
\hline 26.9 & -82.6 & 9.8 & $\mathrm{R}$ cuneus & 512 \\
\hline 6.9 & 20.7 & -8.8 & R ACC (BA 32) & 296 \\
\hline 10.4 & 36.9 & -0.3 & R ACC & 224 \\
\hline-49.3 & 36.3 & 9.5 & L IFG (BA 46) & 168 \\
\hline 4.5 & 25.8 & 24.5 & R ACC (BA 24) & 120 \\
\hline
\end{tabular}

Table 3. (continued)

\begin{tabular}{|c|c|c|c|c|}
\hline \multicolumn{3}{|c|}{ Activation Focus } & \multirow[b]{2}{*}{ Region $\left(>100 \mathrm{~mm}^{3}\right)$} & \multirow[b]{2}{*}{ Size } \\
\hline$x$ & $y$ & $z$ & & \\
\hline \multicolumn{5}{|c|}{ Sadness-Anger } \\
\hline \multicolumn{5}{|c|}{ Sadness > Anger } \\
\hline-3.6 & 46.5 & 27.7 & L MFG (BA 9) & 2088 \\
\hline 36.9 & 7.1 & 17.3 & $\mathrm{R}$ insula (BA 13) & 1528 \\
\hline-11.5 & 16.8 & -8.9 & Left insula ${ }^{a}$ & 1328 \\
\hline 2.3 & 11.3 & 6.2 & $\mathrm{R}$ caudate head ${ }^{\mathrm{a}}$ & 912 \\
\hline 43.6 & -67.1 & 4.0 & R ITG & 784 \\
\hline-37.8 & 35.3 & -9.0 & L MFG (BA 11) & 768 \\
\hline-35.6 & 49.2 & -4.0 & L MFG (BA 10) & 736 \\
\hline 41.4 & -51.7 & -23.6 & $\mathrm{R}_{\text {cerebellum }}{ }^{\mathrm{a}}$ & 608 \\
\hline-3.5 & -37.0 & -3.1 & L cerebellum $^{\mathrm{a}}$ & 400 \\
\hline-16.5 & -11.4 & 12.5 & L thalamus ${ }^{\mathrm{a}}$ & 400 \\
\hline 44.1 & 21.5 & 12.5 & R IFG (BA 45) & 328 \\
\hline 39.3 & 21.7 & -4.4 & R IFG (BA 47) & 328 \\
\hline 12.9 & -4.1 & -6.1 & R basal ganglia (GP) & 256 \\
\hline-0.7 & -19.5 & 10.9 & L thalamus ${ }^{\mathrm{a}}$ & 216 \\
\hline-32.4 & 11.7 & -13.6 & L IFG (BA 13) & 192 \\
\hline 22.7 & 8.4 & -6.1 & R basal ganglia (Put) & 176 \\
\hline-6.6 & 59.9 & 2.7 & L medFG (BA 10) & 152 \\
\hline 32.9 & -22.0 & 18.8 & $\mathrm{R}$ insula (BA 13) & 120 \\
\hline
\end{tabular}

Anger $>$ Sadness

$\begin{array}{rrrll}19.9 & -18.8 & -9.0 & \text { R PHG } & 2536 \\ -43.8 & 22.4 & -4.1 & \text { L IFG (BA 47) } \\ -46.5 & -74.0 & -10.7 & \text { L fusiform gyrus } & 1976 \\ & & & & 1760\end{array}$

Anger-Fear

Anger $>$ Fear

$\begin{array}{rrrll}-47.1 & 25.2 & -2.9 & \text { L IFG (BA 47) } & 784 \\ 48.6 & 13.9 & 30.1 & \text { R MFG (BA 9) } & 520 \\ -7.9 & -34.2 & 31.9 & \text { L cingulate gyrus } & \text { a } \\ 20.2 & -20.8 & -7.9 & \text { R PHG } & 176 \\ & & & & 152\end{array}$

Fear $>$ Anger

\begin{tabular}{rrrlr}
-21.4 & -6.9 & -10.6 & L basal ganglia (Put) $^{\mathrm{a}}$ & 3688 \\
33.8 & -4.3 & -4.7 & R insula (BA 13) & 3512 \\
28.7 & -52.6 & -7.9 & R cerebellum $^{\mathrm{a}}$ & 2080 \\
-37.5 & -52.5 & -16.0 & L fusiform gyrus $^{\mathrm{a}}$ & 920 \\
3.4 & 47.9 & 5.2 & R ACC (BA 32) $^{\mathrm{a}}$ & 440 \\
42.5 & -40.2 & 20.5 & R insula (BA 13) $^{\mathrm{a}}$ & 304 \\
\hline
\end{tabular}


Table 3. (continued)

\begin{tabular}{|c|c|c|c|c|}
\hline \multicolumn{3}{|c|}{ Activation Focus } & \multirow[b]{2}{*}{ Region $\left(>100 \mathrm{~mm}^{3}\right)$} & \multirow[b]{2}{*}{ Size } \\
\hline$x$ & $y$ & $z$ & & \\
\hline 37.5 & 10.3 & 19.6 & $\mathrm{R}$ insula $(\mathrm{BA} 13)^{\mathrm{a}}$ & 296 \\
\hline-35.8 & 4.3 & 1.5 & $\mathrm{~L}$ insula & 248 \\
\hline 41.8 & 33.6 & 15.3 & R MFG (BA 46) & 224 \\
\hline-21.1 & -34.1 & -0.7 & $\mathrm{LPHG}^{\mathrm{a}}$ & 208 \\
\hline 4.8 & 34.0 & 6.0 & R ACC (BA 24) & 144 \\
\hline
\end{tabular}

Anger-Disgust

Anger $>$ Disgust

$\begin{array}{rrrl}-46.0 & 25.9 & -2.9 & \text { L IFG (BA 47) } \\ -45.6 & -74.2 & -11.2 & \text { L fusiform gyrus } \\ 19.4 & -20.9 & -8.4 & \text { R PHG (BA 35) } \\ 49.1 & 16.2 & 30.6 & \text { R MFG (BA 9) }\end{array}$

Disgust $>$ Anger

\begin{tabular}{|c|c|c|c|}
\hline 32.0 & 5.3 & -2.2 & $\mathrm{R}$ basal ganglia (Put) ${ }^{\mathrm{a}}$ \\
\hline-33.5 & 14.2 & -3.2 & L insula (BA 13) \\
\hline-22.6 & -70.8 & -6.0 & $\mathrm{~L}_{\text {lingual gyrus }}^{\mathrm{a}}$ \\
\hline-19.5 & -2.9 & -15.5 & L PHG \\
\hline-1.3 & 43.4 & 40.1 & L medFG (BA 8) \\
\hline-40.9 & -52.7 & -8.4 & L fusiform gyrus ${ }^{\mathrm{a}}$ \\
\hline 6.9 & 20.7 & -8.8 & R ACC (BA 32) \\
\hline 10.4 & 36.5 & -0.2 & R ACC \\
\hline 41.9 & -60.3 & -6.24 & $\mathrm{R}$ fusiform gyrus \\
\hline-18.5 & -50.5 & -3.49 & L PHG (BA 19) \\
\hline-45.9 & -10.1 & -20.77 & L temporal lobe (BA 20) \\
\hline-49.2 & 36.3 & 9.38 & L IFG (BA 46) \\
\hline 4.4 & 25.7 & 24.46 & R ACC (BA 24) \\
\hline 41.6 & 34.9 & 16.13 & R MFG (BA 46) ${ }^{\mathrm{a}}$ \\
\hline-12.0 & 38.0 & -7.01 & L medFG (BA 10) \\
\hline
\end{tabular}

Happiness-Anger

Happiness > Anger

$\begin{array}{rrrl}-0.5 & 39.5 & 8.3 & \text { L ACC (BA 32) } \\ 58.4 & -40.6 & 14.4 & \text { R STG (BA 22) } \\ -4.2 & -91.8 & 2.2 & \text { L lingual gyrus } \\ -18.2 & -9.8 & 17.0 & \text { L thalamus } \\ -3.2 & 59.5 & 0.2 & \text { L medFG (BA 10) } \\ -35 & -31.5 & 18.0 & \text { L insula (BA 13) }\end{array}$

Anger $>$ Happiness

$\begin{array}{lll}-43.4 & 21.4 & -4.5\end{array}$ L IFG (BA 47) ${ }^{\mathrm{a}}$

1456

1008

936

648

280

240

232

200

176

152

144

128

128
Table 3. (continued)

\begin{tabular}{rrrllr}
\hline \multicolumn{3}{c}{ Activation Focus } & & \\
\cline { 1 - 3 }$x$ & \multicolumn{1}{c}{$y$} & \multicolumn{1}{c}{$z$} & & Region $\left(>100 \mathrm{~mm}^{3}\right)$ & Size \\
\hline 19.6 & -19.8 & -8.6 & R PHG & 808 \\
48.0 & 13.2 & 30.2 & R IFG (BA 9) & 752 \\
36.4 & 6.3 & -10.7 & R IFG (BA 13) & 344 \\
-43.9 & 10.6 & 26.3 & L IFG (BA 9) & 336 \\
-11.0 & 24.0 & -16.0 & L medFG (BA 25) & 112
\end{tabular}

\section{Happiness-Fear}

Happiness > Fear

$\begin{array}{rrrll}55.3 & -45.7 & 9.8 & \text { R STG (BA 22) } & 1592 \\ -2.7 & 38.3 & 9.8 & \text { L ACC (BA 32) } & 776 \\ -18.3 & -8.7 & 16.7 & \text { L thalamus } & 672 \\ -1.9 & 58.6 & -1.9 & \text { L medFG (BA 10) } & 592 \\ -5.3 & 31.6 & -2.8 & \text { R ACC (BA 32) } & 192 \\ -36.7 & -31.4 & 17.9 & \text { L insula (BA 13) } & 144\end{array}$

Fear $>$ Happiness

$\begin{array}{rrrlr}-21.1 & -6.2 & -10.8 & {\text { L } \text { amygdala }^{\mathrm{a}}} & 3192 \\ 24.6 & -8.3 & -11.3 & {\text { R } \text { amygdala }^{\mathrm{a}}} & 2600 \\ 27.8 & -52.7 & -9.3 & \text { R fusiform gyrus }^{\mathrm{a}} & 2072 \\ 42.9 & 2.7 & -1.8 & \text { R STG }^{\mathrm{a}} & 2056 \\ -38.1 & 22.1 & -7.7 & \text { L IFG (BA 47) } & 896 \\ -46.1 & -63.3 & -4.2 & \text { L middle Occ gyrus }^{\mathrm{a}} & 568 \\ -35.3 & 5.0 & 1.0 & \text { L insula } & 424 \\ 38.2 & 10.2 & 19.9 & \text { R insula (BA 13) } & 288 \\ 42.8 & -40.7 & 20.4 & \text { R insula (BA 13) } & 192 \\ 13.3 & 29.5 & 13.9 & \text { R ACC (BA 32) } & 168 \\ 5.3 & 47.9 & 4.6 & \text { R medFG (BA 10) } & 120\end{array}$

Sadness-Fear

Sadness $>$ Fear

\begin{tabular}{rrrlr}
-3.7 & 47.0 & 27.5 & L medFG (BA 9) $^{\mathrm{a}}$ & 2840 \\
-11.6 & 17.5 & -8.5 & L caudate head $^{\mathrm{a}}$ & 1248 \\
44.2 & 5.5 & 28.1 & R IFG (BA 9) & 816 \\
-39.0 & 35.2 & -8.8 & L cerebellum $^{\mathrm{a}}$ & 752 \\
41.1 & -51.7 & -22.6 & R MFG (BA 10) & 704 \\
2.3 & 7.8 & 61.7 & R precentral gyrus & 592 \\
-36.7 & 49.2 & -5.7 & R cerebellum & a \\
-4.4 & -38.4 & -4.8 & R thalamus & 560 \\
-16.5 & -10.5 & 12.2 & R MFG (BA 11) & 552 \\
\hline
\end{tabular}


Table 3. (continued)

\begin{tabular}{rrrllr}
\hline \multicolumn{4}{c}{ Activation Focus } & & \\
\cline { 1 - 3 }$x$ & \multicolumn{1}{c}{$y$} & \multicolumn{1}{c}{$z$} & & \multicolumn{1}{c}{ Region $\left(>100 \mathrm{~mm}^{3}\right)$} & Size \\
\hline 44.2 & -62.9 & 8.4 & R cerebellum $^{\mathrm{a}}$ & 464 \\
-47.4 & -6.7 & 41.1 & L caudate head $^{\mathrm{a}}$ & 456 \\
-60.0 & -14.7 & -0.7 & L MFG (BA 47) & L & 312 \\
39.4 & 39.0 & -10.7 & R medFG (BA 10) & 280 \\
-0.6 & -19.9 & 10.9 & & L basal ganglia (Put) & 112
\end{tabular}

Fear $>$ Sadness

$$
\begin{array}{rrrl}
-20.4 & -7.1 & -10.2 & \text { L PHG/amygdala } \\
24.0 & -10.3 & -10.4 & \text { R midbrain } \\
32.2 & -52.9 & -8.6 & \text { R fusiform gyrus } \\
42.5 & 1.1 & 0.2 & \text { R insula (BA 13) } \\
4.3 & 47.4 & 3.6 & \text { R ACC (BA 32) } \\
-38.4 & -52.1 & -17.9 & \text { L IFG (BA 47) }
\end{array}
$$

\section{Sadness-Disgust}

\begin{tabular}{|c|c|c|c|c|}
\hline \multicolumn{3}{|c|}{ Activation Focus } & \multirow[b]{2}{*}{ Region $\left(>100 \mathrm{~mm}^{3}\right)$} & \multirow[b]{2}{*}{ Size } \\
\hline$x$ & $y$ & $z$ & & \\
\hline \multicolumn{5}{|c|}{ Fear-Disgust } \\
\hline \multicolumn{5}{|c|}{ Fear $>$ Disgust } \\
\hline-20.6 & -8.5 & -9.7 & $\mathrm{~L}$ amygdala ${ }^{\mathrm{a}}$ & 2264 \\
\hline 24.5 & -51.5 & -7.6 & R PHG (BA 19) ${ }^{\mathrm{a}}$ & 992 \\
\hline 42.6 & 6.4 & -2.1 & $\mathrm{R}$ insula (BA 13) ${ }^{\mathrm{a}}$ & 600 \\
\hline-38.8 & -54.7 & -16.0 & L cerebellum & 432 \\
\hline 4.1 & 48.3 & 5.2 & $\mathrm{R} \operatorname{ACC}(\mathrm{BA} 32)^{\mathrm{a}}$ & 352 \\
\hline 25.0 & -11.0 & -10.4 & $\mathrm{R}$ amygdala ${ }^{\mathrm{a}}$ & 328 \\
\hline-20.8 & -33.7 & -0.3 & L PHG (BA 27) & 256 \\
\hline 42.2 & -39.8 & 20.1 & $\mathrm{R}$ insula (BA 13) ${ }^{\mathrm{a}}$ & 208 \\
\hline 13.3 & 29.0 & 13.8 & $\mathrm{R} \operatorname{ACC}(\mathrm{BA} 32)^{\mathrm{a}}$ & 112 \\
\hline \multicolumn{5}{|c|}{ Disgust $>$ Fear } \\
\hline 34.2 & 22.7 & -0.9 & $\mathrm{R}$ basal ganglia ${ }^{\mathrm{a}}$ & 2328 \\
\hline-25.6 & 27.8 & -10.0 & L IFG (BA 47) & 2192 \\
\hline-38.7 & 3.6 & 0.9 & L insula (BA 13) & 2088 \\
\hline 26.5 & 4.4 & -14.6 & R IFG (BA 47) ${ }^{\mathrm{a}}$ & 1792 \\
\hline 28.1 & -5.2 & 3.5 & $\mathrm{R}$ basal ganglia ${ }^{\mathrm{a}}$ & 1544 \\
\hline-1.5 & 43.5 & 39.9 & L medFG (BA 8) & 888 \\
\hline-19.6 & -71.4 & -6.1 & L lingual gyrus ${ }^{\mathrm{a}}$ & 736 \\
\hline 27.0 & -82.3 & 10.1 & $\mathrm{R}$ cuneus (BA 30) & 448 \\
\hline-47.3 & -43.7 & 3.9 & L MTG (BA 22) & 432 \\
\hline-13.0 & 38.2 & -6.7 & L medFG (BA 10) & 256 \\
\hline 10.6 & 36.6 & -0.9 & R ACC & 136 \\
\hline 4.1 & 25.5 & 24.7 & R ACC (BA 24) & 120 \\
\hline
\end{tabular}

Sadness $>$ Disgust

$\begin{array}{rrrl}41.1 & 5.8 & 24.1 & \text { R IFG (BA 9) } \\ -4.1 & 48.1 & 26.9 & \text { L medFG (BA 9) }^{\mathrm{a}} \\ 40.4 & -51.3 & -22.6 & \text { R cerebellum }^{\mathrm{a}} \\ -4.5 & -38.7 & -4.6 & \text { L cerebellum }^{\mathrm{a}} \\ -13.0 & 16.2 & -9.1 & \text { L insula }^{\mathrm{a}} \\ 1.4 & 11.0 & 6.2 & \text { R caudate head }^{\mathrm{a}} \\ -16.5 & -10.7 & 14.0 & \text { L thalamus }^{2} \\ 2.3 & 7.7 & 61.6 & \text { R MFG (BA 47) }^{\mathrm{a}} \\ -47.3 & -6.9 & 41.0 & \text { L precentral gyrus } \\ -40.3 & 35.7 & -8.4 & \text { L MFG (BA 47) } \\ -37.7 & 49.5 & -6.6 & \text { R MFG (BA 11) } \\ -29.3 & 49.3 & 4.0 & \text { L MFG (BA 10) }\end{array}$

Disgust $>$ Sadness

\begin{tabular}{rrrll}
-33.7 & 15.3 & -3.6 & L IFG (BA 47) & 6392 \\
30.5 & -3.8 & -5.8 & R STG (BA 22) & 6288 \\
35.6 & 23.3 & 0.9 & R insula (BA 13) & 1144 \\
-22.8 & -69.8 & -4.3 & L lingual gyrus & a \\
-49.9 & 19.1 & 26.3 & L IFG (BA 9) & 600 \\
-41.7 & -56.2 & -7.8 & L fusiform gyrus & 560 \\
-19.5 & -2.8 & -16.6 & L PHG/amygdala & 448 \\
40.4 & -57.7 & -8.6 & R fusiform gyrus & 432 \\
-13.0 & 38.3 & -7.5 & L medFG (BA 10) & 136 \\
-2.5 & 43.7 & 42.5 & L medFG (BA 8) & 112 \\
\hline
\end{tabular}

Table 3. (continued)

Labels (e.g., "Happiness > Sadness") indicate regions of consistently greater activity (i.e., activation likelihood) for the first emotion relative to the second. Each cluster greater than $400 \mathrm{~mm}^{3}$ in size is reported, along with the weighted central activation likelihood focus, the region corresponding to the cluster with the highest ALE score within the cluster, and the total cluster size in $\mathrm{mm}^{3}$. Additional clusters of interest that surpassed a threshold of $100 \mathrm{~mm}^{3}$ were also reported. L and R indicate ALE clusters located in the left and right hemispheres, respectively. Inf $=$ inferior; Occ $=$ occipital; GP $=$ globus pallidus; Put $=$ putamen; $\mathrm{PHG}=$ parahippocampal gyrus. BA labels are provided to differentiate ALE clusters in larger regions that occur in multiple contrasts.

${ }^{\mathrm{a}}$ Indicates regions that overlapped with the reanalysis that involved only studies that used facial expressions.

to the analysis, by allowing additional ALE clusters to be identified that discriminated between basic emotions.

\section{Role of Stimulus Differences}

The studies contributing to the activation foci in the ALE analysis used a wide range of experimental materials and methods to examine emotion, such as facial expressions 
Table 4. ALE Activation Clusters Differentiating Each Basic Emotion State for Reanalysis with Reduced Data Set

\begin{tabular}{|c|c|}
\hline Contrast & Regions \\
\hline Happiness > Sadness & L ACC [BA 32] (1264 $\left.\mathrm{mm}^{3}\right)$, R MTG, L MTG, L insula, R STG \\
\hline Sadness > Happiness & $\begin{array}{l}\text { R ACC [BA 24] }\left(2096 \mathrm{~mm}^{3}\right) \text {, L caudate head, R insula, L medFG, L cerebellum, L SFG, L MFG, R insula, } \\
\text { R MFG, L thalamus, R medFG }\end{array}$ \\
\hline Happiness > Anger & L ACC [BA 32] $\left(1216 \mathrm{~mm}^{3}\right)$, L cerebellum, R MTG, L MTG, R Put, L insula, L thalamus \\
\hline Anger $>$ Happiness & $\begin{array}{l}\text { R IFG (1552 } \mathrm{mm}^{3} \text { ), R thalamus, L STG, L cingulate gyrus, R PHG, L IFG, L thalamus, L cerebellum, } \\
\text { R cingulate gyrus, R MFG, L MFG }\end{array}$ \\
\hline Happiness > Fear & L ACC [BA 24] (1240 mm³), R MTG, L medFG, R STG, R posterior cingulate, L insula, R ACC [BA 32] \\
\hline Fear $>$ Happiness & L amygdala $\left(3504 \mathrm{~mm}^{3}\right), \mathrm{R}$ insula, $\mathrm{R}$ Put, $\mathrm{R}$ thalamus, $\mathrm{R}$ cingulate gyrus, $\mathrm{L}$ SFG, L IFG, R PHG, L thalamus \\
\hline Happiness $>$ Disgust & $\begin{array}{l}\left.\text { L ACC [BA 24] (2528 } \mathrm{mm}^{3}\right) \text {, L medFG, L cerebellum, R MTG, L MTG, R STG, R supramarginal gyrus, L GP, } \\
\text { L ACC [BA 32], L thalamus, L insula, R Put }\end{array}$ \\
\hline Disgust $>$ Happiness & L insula $\left(3024 \mathrm{~mm}^{3}\right)$, R STG, R Put, R postcentral gyrus, R cuneus, L thalamus, R IFG (Insula) \\
\hline Sadness > Anger & L MFG (1068 mm³), R MFG, R caudate head, R insula, L medFG, L thalamus, R IFG, L MTG \\
\hline Anger $>$ Sadness & L IFG, (2256 mm³), R cingulate, L fusiform gyrus, R PHG \\
\hline Sadness > Fear & L caudate head (912 $\mathrm{mm}^{3}$ ), R MFG, R IFG, R thalamus, R cerebellum, L Put \\
\hline Fear $>$ Sadness & $\mathrm{L}$ amygdala $\left(2734 \mathrm{~m}^{3}\right), \mathrm{R}$ insula, $\mathrm{R}$ fusiform gyrus, $\mathrm{L}$ IFG \\
\hline Sadness $>$ Disgust & L medFG $\left(856 \mathrm{~mm}^{3}\right.$ ), R caudate head, L cerebellum, L thalamus, R MFG, L MFG, L medFG \\
\hline Disgust $>$ Sadness & R STG $\left(5478 \mathrm{~mm}^{3}\right)$, L insula, L amygdala, $\mathrm{R}$ insula, L fusiform, $\mathrm{R}$ insula, $\mathrm{R}$ Put \\
\hline Anger $>$ Fear & L IFG (982 mm³), L MFG, R MFG, L cingulate gyrus \\
\hline Fear $>$ Anger & R insula (4913 mm³), L Put, L amygdala, R ACC [BA 32], L insula, L fusiform gyrus, L PGH, L thalamus \\
\hline Anger $>$ Disgust & $\begin{array}{l}\text { L IFG }\left(1092 \mathrm{~mm}^{3}\right) \text {, L STG, L fusiform gyrus, R PHG, L cerebellum, R ACC [BA 32], L cingulate gyrus, } \\
\text { L thalamus, L MFG, R MFG, R cingulate gyrus, L Put, L medFG }\end{array}$ \\
\hline Disgust $>$ Anger & R STG $\left(1608 \mathrm{~mm}^{3}\right)$, R GP, R postcentral gyrus, L thalamus, R IFG (Insula), L MTG \\
\hline Fear $>$ Disgust & $\begin{array}{l}\text { L amygdala ( } 4544 \mathrm{~mm}^{3} \text { ), R cingulate gyrus, L SFG, R insula, R precentral gyrus, L thalamus, R thalamus, } \\
\text { R fusiform gyrus, L IFG, R STG, R PHG, R Put, R thalamus, R ACC [BA 32] }\end{array}$ \\
\hline Disgust $>$ Fear & R Put $\left(2200 \mathrm{~mm}^{3}\right)$, L GP, R postcentral gyrus, L insula \\
\hline
\end{tabular}

Each cluster greater than $400 \mathrm{~mm}^{3}$ is reported. The region corresponding to the largest cluster is reported first, with the total cluster size listed in parentheses. Additional clusters of interest that surpassed a threshold of $100 \mathrm{~mm}^{3}$ are also reported. $\mathrm{L}$ and $\mathrm{R}$ indicate ALE clusters located in the left and right hemispheres, respectively. Inf $=$ inferior; $\mathrm{GP}=$ globus pallidus; Put $=$ putamen; $\mathrm{PGH}=$ parahippocampal gyrus. BAs are provided to differentiate activations in larger regions that occur in multiple contrasts.

of emotion, emotional pictures, films, and scripts. Because studies differed in the frequency with which they used specific types of stimuli and elicitation methods, we examined whether such methodological differences could have contributed to the neural differences observed here. Notably, facial expressions of emotion were the most frequently used stimulus type for studies examining all basic emotions except for disgust, where emotional pictures were the second most frequent stimulus type. Specifically, facial expressions were used as stimuli in 14 of 30 happiness studies, 11 of 33 sadness studies, 10 of 16 anger studies, 24 of 37 fear studies, and 9 of 29 disgust studies (11 of 29 disgust studies used picture stimuli). Because of insufficient numbers of associated studies, it was not possible to examine the differential effects of every type of stimulus. Accordingly, we focused on the potential role of the most commonly used stimulus type, facial expressions.
To investigate the potential effects of stimulus material on the activation patterns associated with a given emotion, we conducted the ALE analysis a second time, including only those studies that used facial expressions as stimuli. In this way, we ruled out the possibility that systematic differences in stimulus type could contribute to activation differences differentiating basic emotions. Based on the hypothesis that stimulus differences did not contribute significantly to our original ALE results, we expected to obtain roughly similar results when we controlled for stimulus differences in this manner, although we also expected that the results would differ somewhat because of the smaller number of studies. The results of this reanalysis confirmed that the ALE results obtained with studies using facial emotion stimuli were similar to the results of the original analyses for each basic emotion. Overall, there was substantial overlap in the number of regional clusters 
identified in both analyses (Table 2). Furthermore, the regions that were central to the differentiation of each basic emotion state in the original analyses were also typically significant in the analysis limited to studies using facial emotion stimuli (Table 3). These results suggest that differences in stimulus type did not drive the primary finding of significant differentiation of emotion states because when the potential effects of stimulus differences were eliminated, the characteristic patterns of neural activation associated with each basic emotion were still observed, and each basic emotion could still be differentiated on the basis of regional activations.

\section{DISCUSSION}

The primary goal of this study was to assess the extent to which the current neuroimaging literature supports the proposal of basic emotion theories that different basic emotion states are associated with consistent, characteristic, and discriminable patterns of brain activity. The results of the ALE meta-analysis supported the predictions of basic emotion theories. Each of the basic emotion states examined (anger, fear, sadness, anger, and disgust) was consistently associated across studies with characteristic patterns of regional brain activity. For example, across a variety of different experimental paradigms and stimuli, we found that fear was associated with increased activation in the amygdala and insula, relative to emotionally neutral stimuli. Importantly, each basic emotion was reliably distinguished or differentiated from the other emotions on the basis of its characteristic pattern of brain activation. Specifically, every pairwise statistical contrast between the activation foci associated with emotion states (e.g., fear vs. anger) in the ALE analysis yielded a set of regional brain activations that reliably differentiated between each pair of emotions. Further, as predicted, the signature patterns of neural activation that characterized each emotion also most consistently differentiated that emotion from other emotions. This is in contrast with other possible scenarios, for example, where the regions that differentiate between emotions could have little overlap with the core, characteristic brain regions consistently activated by each emotion. Finally, the associations between emotion states and regions of brain activation identified in our ALE meta-analysis of the neuroimaging literature converge with the findings from other approaches including neuropsychological studies (e.g., Adolphs, et al., 1994) and studies of nonhuman animals (e.g., Davis, 1992, 1994).

The current meta-analysis found that all five basic emotion states were associated with consistent and discriminable patterns of neural activation (Figure 2). Happiness consistently activated rostral ACC and right STG, and activity in both regions differentiated happiness from sadness, anger, fear, and disgust (ACC only). Sadness consistently activated MFG and head of the caudate/subgenual ACC, and activity in both regions reliably differentiated sadness from happiness, anger, fear, and disgust. Anger consistently activated IFG and PHG, and both regions differentiated anger from all other emotion states. Fear consistently activated amygdala and insula, and these regions differentiated fear from happiness, sadness, anger (insula only), and disgust (posterior insula). Disgust consistently activated IFG/ anterior insula, and these regions reliably differentiated disgust from all other emotion states. Together, these findings support the predictions of basic emotion theories by demonstrating that basic emotion states are associated with consistent patterns of brain activation and that these patterns differ significantly between emotions.

In contrast to the current meta-analysis, two previous meta-analyses (e.g., Murphy et al., 2003; Phan et al., 2002) found more limited support for basic emotion theories. Phan et al. (2002), using a meta-analytic method based on counts of activated regions, found limited evidence for consistent associations between brain regions and basic emotions. For example, fear was more consistently associated with amygdala activation than any other emotion state, and sadness exhibited a greater association with subcallosal cingulate cortex activation in comparison to other emotions. Anger, happiness, and disgust did not consistently activate any brain region more than other emotions states. However, Phan et al. did not directly contrast activation patterns associated with each basic emotion, so the extent to which these activations composed patterns that discriminated between basic emotions could not be addressed. Murphy et al. (2003) did address this question and found reliably different spatial patterns of activation neural correlates for fear (amygdala), disgust (insula), and anger (globus pallidus and lateral OFC). However, happiness and sadness were not reliably differentiated, and the spatial divisions used in that study were too large to address the issue of discriminability at the level of specific brain regions.

Our meta-analysis differed from these previous metaanalyses in two important ways. We included a substantial amount of new data from thirty studies that were not included in the largest meta-analysis to date, and we used the more spatially sensitive ALE method. To determine the extent to which our method (ALE) versus the inclusion of more data contributed to the increased ability to differentiate between neural patterns associated with basic emotions, we used the ALE method to analyze the smaller data set analyzed by Murphy et al. (2003) and compared the results to those of the current meta-analysis. The results demonstrated that the ALE method was able to differentiate between all of the emotion states, including the pair of emotions that the previous meta-analysis was not able to differentiate. These findings suggest that both the increased sensitivity of the ALE method and the inclusion of additional studies contributed to the increased ability to discriminate among emotions.

Converging evidence from several domains suggests that discrete basic emotions are psychologically, physiologically, and neurologically discriminable (e.g., Rainville, Bechara, Naqvi, \& Damasio, 2006; Murphy et al., 2003; Ekman, Levenson, \& Friesen, 1983). For example, therapeutic 
intervention studies of depression have demonstrated that reduction in depressive symptoms is associated with increased activity in BA 24 (cingulate cortex), when deep brain stimulation or cognitive behavioral therapy is used (Mayberg et al., 2005; Goldapple et al., 2004), and decreased activity in BA 9 (medial frontal cortex), when cognitive behavioral therapy is used (Goldapple et al., 2004). Mood fluctuations associated with happiness versus sadness may be supported by subregions of BA 24 (e.g., subgenual ACC; Mayberg et al., 2005) that have subcortical projection to the brainstem and thalamus (areas that are involved in circadian rhythm maintenance; Barbas, Saha, RempelClower, \& Ghashghaei, 2003; Ongur, An, \& Price, 1998). These findings correspond with our results that implicate ACC (BA 24) and medFG (BA 9) are uniquely associated with happiness and sadness, respectively. Similarly, our results suggest an important role for IFG in anger, and this finding is complemented by the results of neuropsychological studies which indicate that damage to the IFG can increase violent and aggressive behaviors, consistent with a proposed regulatory role for the IFG in the expression of anger (Grafman et al., 1996; Damasio, Grabowski, Frank, Galaburda, \& Damasio, 1994). The IFG may be engaged during exposure to angering stimuli as an automatic control to curb the potential for an overreaction such as unbridled rage. In addition, we found that disgust was associated with activity in the insula, and stimulation of this region has been shown to induce nausea (Penfield \& Faulk, 1955) and unpleasant sensations in the throat mouth and nose (Krolak-Salmon et al., 2003); both of which are involved in the experience of disgust. The visceral feeling that people experience in response to a disgusting stimulus may therefore reflect automatic simulation of these sensations, supported by the insula. Finally, the current meta-analytic review confirmed an important functional role for the amygdala in fear. The relationship between amygdala and fear is perhaps the most robust structure-function association found across studies, with converging evidence from metaanalyses of neuroimaging studies (e.g., Murphy et al., 2003; Phan et al., 2002), animal models of fear (Davis, 1994), single-unit recording studies (Maren, 2001), and human lesion studies (Adolphs et al., 1994). The amygdala has been shown to direct attention to threat cues by modulating activity in primary visual cortex, as evidenced by effective connectivity (Pessoa, McKenna, Gutierrez, \& Ungerleider, 2002) and lesion research (Vuilleumier, Richardson, Armony, Driver, \& Dolan, 2004). In addition, it has been suggested that amygdala activity may also indirectly influence thought and behavior through the modulation of prefrontal activity (Miller \& Cohen, 2001), although this claim requires further exploration. A fearful response to a threatening stimulus may recruit the amygdala to focus attention to relevant cues and initiate an appropriate response to the threat.

Although our goal was to investigate the neural activations associated with basic emotions across a variety of contexts and elicitation methods, it is important to note that certain stimulus types were represented more than others in the studies comprising our meta-analysis. For example, facial emotion stimuli were the most frequently used type of stimulus in studies of happiness, sadness, anger, and fear. To examine the potential influence of stimulus differences on the results of our meta-analysis, we conducted an additional ALE analysis limited to studies that used facial expressions as stimuli. The results demonstrated that all five basic emotions were associated with unique and reliable patterns of neural activation, even when the analysis was limited to one stimulus type. Furthermore, the regions identified by this analysis overlapped with the regions identified by the original consistency and discriminability analyses. These findings suggest that the primary finding, that the ALE analysis could differentiate between basic emotions on the basis of neuroimaging evidence, was not driven by stimulus material differences. Because the majority of neuroimaging studies used facial expression stimuli, a remaining issue is the extent to which these findings generalize to other emotional stimuli. As a first step toward addressing this issue, we examined all the studies that did not use facial emotion stimuli, in an ALE analysis, and observed a broadly similar pattern of regions differentiating basic emotions. These results provide some preliminary evidence to suggest that our primary ALE results are not unique to studies using facial emotion, but these results should be viewed as only preliminary because of both the substantially smaller data set (limiting the applicability of the ALE method) and variation across basic emotions in the number of studies that used stimulus types. As additional neuroimaging studies continue to adopt a wider range of stimuli, future meta-analyses will be able to better address this issue.

Regarding limitations of this study, the spatial sensitivity of the current meta-analysis was limited by the resolution of the neuroimaging data in the studies analyzed (approximately 64 cubic mm voxels for fMRI). Subsequent data processing steps and summarization for publication further reduced the effective spatial resolution in individual studies. Another potential source of bias was the fact that a small minority of studies (12\% of foci from all studies) gave preference in their analyses to a priori ROIs by using more lenient thresholds for these regions, which would tend to increase the representation of these regions in the ALE analysis. Notably, the majority (72\%) of these studies examined the neural correlates of fear and disgust, and thus any potential bias would be primarily limited to these two basic emotions. We examined the effect of excluding these foci obtained with more lenient thresholds from the ALE analyses and found that their exclusion resulted in minimal and nonsignificant changes in the outcome of the meta-analysis.

The ALE method also makes some simplifying assumptions that may affect the relative influence of individual activations and individual studies. All activation maxima above the significance threshold adopted in a particular study are given equivalent weight in the analysis, so that 
variations in activation intensity are not accounted for. Similarly, studies with greater numbers of activation maxima will contribute more to the ALE map than studies with fewer maxima, although inspection of our individual studies did not reveal any systematic relationship between the number of maxima per study and the results of the consistency and discriminability analyses. In addition to these considerations, the requirements of the analysis (e.g., analyses of whole-brain data) necessarily limited the number of studies that were included in the review. Another potential limitation includes publication biases such as the file-drawer problem (tendency for null findings not to be published), which is unavoidable.

The ALE approach taken here assessed correspondences between emotional processing and individual brain regions rather than networks of regions. However, interactions between brain regions have been demonstrated to contribute importantly to emotion processing, and thus future meta-analyses should examine interactions and functional networks. Furthermore, we cannot conclude that these results reflect brain regions associated with the induction of basic emotion states because, like all previous meta-analytic studies, we included studies that addressed a wide range of emotion-related processes so that we could investigate the core neural signatures associated with basic emotions across a variety of contexts. As the neuroimaging literature progressively incorporates a wider range of stimuli and methods exploring the neural correlates of basic emotions, this will facilitate the characterization of the effects of induction method and stimulus material.

Although we focused on differentiating basic emotions on the basis of brain activation patterns, a recent metaanalysis used a complementary approach and a different voxel-based meta-analytic method (multilevel kernel density analysis) to explore the functional grouping of emotionrelated activations in the brain (Kober et al., 2008). This study used a data-driven approach that ignored emotion labels such as happiness and sadness. Instead, Kober et al. (2008) investigated the multivariate patterns of coactivation that emerged when activations from neuroimaging studies of emotion are examined, identifying six functionally distributed networks. Because Kober et al. (2008) explicitly avoided analyzing activations on the basis of basic emotion categories, it is difficult to compare between their results and those of the current study. The current meta-analysis also did not examine contextual, linguistic, and other influences on emotion states and their neurobiological correlates. We acknowledge that the experience and interpretation of emotional states can be strongly influenced by situational factors, both internal and external, and thus brain activity would be expected to reflect these factors. However, we sought to investigate the reliability of neural patterns associated with basic emotion categories and thus did not explore the factors contributing to their variability here.

Emotions have been characterized by both dimensional and categorical theoretical frameworks. Dimensional views of emotion have proposed that emotions can be character- ized in terms of component dimensions such as arousal (emotional strength) and valence (pleasantness vs. unpleasantness). The dimensional approach to emotion has proven highly successful in accounting for a wide range of emotional phenomena and is theoretically more parsimonious than categorical approaches such as basic emotion theories (Lang, Bradley, \& Cuthbert, 1990; Watson \& Tellegen, 1985). Although dimensional and basic emotion theories have sometimes been characterized as being incompatible in some respects (e.g., Barrett, 2006), they are not necessarily mutually exclusive characterizations of emotional experience. A hybrid view combining dimensional descriptions of emotion states in terms of arousal and valence with additional characterization provided by basic emotion categories would be consistent with the current findings. For example, whereas a dimensional description in terms of arousal and valence can concisely characterize key aspects of emotional reactions to a photograph eliciting disgust, the basic emotion categorization of disgust captures facets of the experience of disgust not conveyed by the dimensional description, such as a somatic state of nauseation, elicitation of a facial expression of disgust, and CNS activation of the consistent and discriminable regional brain activations identified in the current study. Regarding the neural substrates corresponding to affective dimensions, several neuroimaging studies have identified discriminable neural correlates of emotional arousal (e.g., amygdala) and valence (e.g., subregions of pFC; Lewis, Critchley, Rotshtein, \& Dolan, 2007; Dolcos, LaBar, \& Cabeza, 2004; Anderson, Christoff, Panitz, De Rosa, \& Gabrieli, 2003). Taken together, the results of these studies and the current metaanalysis results indicate that both dimensional views and basic emotion views are supported by neuroimaging studies in the sense that the constructs associated with each view have identifiable neural correlates as assessed with neuroimaging. Further research into the interplay between neural mechanisms underlying basic emotions and corresponding mechanisms associated with arousal and valence dimensions will help elucidate how each contributes to emotional experience and behavior.

\section{Acknowledgments}

The authors are grateful to James Rilling for his comments on an earlier draft and to Angela Laird for correspondence and assistance regarding ALE.

Reprint requests should be sent to Stephan Hamann, Department of Psychology, 36 Eagle Row, Emory University, Atlanta, GA 30322, or via e-mail: shamann@emory.edu.

\section{REFERENCES}

Studies included in the ALE meta-analysis are preceded in the References section by an asterisk.

*Aalto, S., Naatanen, P., Wallius, E., Metsahonkala, L., Stenman, H., Niemi, P. M., et al. (2002). Neuroanatomical substrata of amusement and sadness: A PET activation study using film stimuli. NeuroReport, 13, 67-73. 
*Aalto, S., Wallius, E., Naatanen, P., Hiltunen, J., Metsahonkala, L., Sipila, H., et al. (2005). Regression analysis utilizing subjective evaluation of emotional experience in PET studies on emotions. Brain Research Protocols, 15, 142-154.

*Abel, K. M. C. A., Allin, M. P. G., Kucharska-Pietura, K., David, A., Andrew, C., Williams, S., et al. (2003). Ketamine alters neural processing of facial emotion recognition in healthy men: An fMRI study. NeuroReport, 14, 387-391.

*Abler, B., Erk, S., Herwig, U., \& Walter, H. (2007). Anticipation of aversive stimuli activates extended amygdala in unipolar depression. Journal of Psychiatric Research, 41, 511-522.

Adolphs, R., Tranel, D., Damasio, H., \& Damasio, A. R. (1994). Impaired recognition of emotion in facial expressions following bilateral damage to the human amygdala. Nature, 372, 669-672.

Anderson, A. K., Christoff, K., Panitz, D. A., De Rosa, E., \& Gabrieli, J. D. E. (2003). Neural correlates of the automatic processing of threat facial signals. Journal of Neuroscience, 23, 5627-5633.

*Ashwin, C., Baron-Cohen, S., Wheelwright, S., O'Riordan, M., \& Bullmore, E. T. (2007). Differential activation of the amygdala and the "social brain" during fearful face-processing in Asperger syndrome. Neuropsychologia, 45, 2-14.

Baas, D., Aleman, A., \& Kahn, R. (2004). Lateralization of amygdala activation: A systematic review of functional neuroimaging studies. Brain Research Reviews, 45, 96-103.

*Baker, S. C., Frith, C. D., \& Dolan, R. J. (1997). The interaction between mood and cognitive function studied with PET. Psychological Medicine, 27, 565-578.

Barbas, H., Saha, S., Rempel-Clower, N., \& Ghashghaei, T. (2003). Serial pathways from primate prefrontal cortex to autonomic areas may influence emotional expression. $B M C$ Neuroscience, 4-25.

Barrett, L. F. (2006). Are emotions natural kinds? Psychological Science, 1, 28-58.

Barrett, L. F., Lindquist, K., Bliss-Moreau, E., Duncan, S., \& Brennan, L. (2007). Of mice and men: Natural kinds of emotion in the mammalian brain? Perspectives on Psychological Science, 2, 297-312.

Barrett, L. F., \& Russell, J. A. (1999). Structure of current affect. Current Directions in Psychological Science, 8, 10-14.

Barrett, L. F., \& Wager, T. (2006). The structure of emotion: Evidence from the neuroimaging studies. Current Directions in Psychological Science, 15, 79-85.

*Beauregard, M., Leroux, J. M., Bergman, S., Arzoumanian, Y., Beaudoin, G., Bourgouin, P., et al. (1998). The functional neuroanatomy of major depression: An fMRI study using an emotional activation paradigm. NeuroReport, 9, 3253-3258.

*Benuzzi, F., Lui, F., Duzzi, D., Nichelli, P. F., \& Porro, C. A. (2008). Does it look painful or disgusting? Ask your parietal and cingulate cortex. Journal of Neuroscience, 28, 923-931.

*Benuzzi, F., Meletti, S., Zamboni, G., Calandra-Buonaura, G., Serafini, M., Lui, F., et al. (2004). Impaired fear processing in right mesial temporal sclerosis: A fMRI study. Brain Research Bulletin, 63, 269-281.

*Blair, R. J. R., Morris, J. S., Frith, C. D., Perrett, D. I., \& Dolan, R. J. (1999). Dissociable neural responses to facial expressions of sadness and anger. Brain, 122, 883-893.

*Buchanan, T. W., Lutz, K., Mirzazade, S., Specht, K., Shah, N. J., Zilles, K., et al. (2000). Recognition of emotional prosody and verbal components of spoken language: An fMRI study. Cognitive Brain Research, 9, 227-238.

*Bystritsky, A., Pontillo, D., Powers, M., Sabb, F. W., Craske, M. G., \& Bookheimer, S. Y. (2001). Functional MRI changes during panic anticipation and imagery exposure. NeuroReport, 12, 3953-3957.

Cacioppo, J. T., Berntson, G. G., Larsen, J. T., Poehlmann, K. M., \& Ito, T. A. (2000). The psychophysiology of emotion. In
M. Lewis \& R. J. M. Haviland-Jones (Eds.), The handbook of emotions (2nd ed., pp. 173-191). New York: Guilford Press. *Damasio, A. R., Grabowski, T. J., Bechara, A., Damasio, H., Ponto, L. L. B., Parvizi, J., et al. (2000). Subcortical and cortical brain activity during the feeling of self-generated emotions. Nature Neuroscience, 3, 1049-1056.

Damasio, H., Grabowski, T., Frank, R., Galaburda, A. M., \& Damasio, A. R. (1994). The return of Phineas Gage: Clues about the brain from the skull of a famous patient. Science, 264, 1102-1105

Darwin, C. (1872). The expression of the emotions in man and animals, 1998 (3rd ed.). New York: Oxford University Press.

Davis, M. (1992). The role of the amygdala in conditioned fear. In J. P. Aggleton (Ed.), The amygdala: Neurobiological aspects of emotion, memory, and mental dysfunction (pp. 255-305). New York: Wiley-Liss.

Davis, M. (1994). The role of the amygdala in emotional learning. International Review of Neurobiology, 36, 225-266.

*Dolan, R. J., Fletcher, P., Morris, J., Kapur, N., Deakin, J. F. W., \& Frith, C. D. (1996). Neural activation during covert processing of positive emotional facial expressions. Neuroimage, 4, 194-200.

Dolcos, F., LaBar, K. S., \& Cabeza, R. (2004). Dissociable effects of arousal and valence on prefrontal activity indexing emotional evaluation and subsequent memory: An event-related fMRI study. Neuroimage, 23, 64-74.

*Dougherty, D. D., Shin, L. M., Alpert, N. M., Pitman, R. K., Orr, S. P., Lasko, M., et al. (1999). Anger in healthy men: A PET study using script-driven imagery. Biological Psychiatry, 46, 466-472

Ekman, P. (1972). Universals and cultural differences in facial expressions of emotion. In J. Cole (Ed.), Nebraska symposium on motivation, 1971 (pp. 207-283). Lincoln: University of Nebraska Press.

Ekman, P. (1992). An argument for basic emotions. Cognition and Emotion, 6, 169-200.

Ekman, P. (1999). Basic emotions. In T. Dalgleish \& M. Power (Eds.), Handbook of cognition and emotion. Sussex, UK: John Wiley \& Sons, Ltd.

Ekman, P., Levenson, R. W., \& Friesen, W. V. (1983). Autonomic nervous system activity distinguishes among emotions. Science, 221, 1208-1210.

*Eugene, F., Levesque, J., Mensour, B., Leroux, J. M., Beaudoin, G., Bourgouin, P., et al. (2003). The impact of individual differences on the neural circuitry underlying sadness. Neuroimage, 19, 354-364.

*Fischer, H., Sandblom, J., Gavazzeni, J., Fransson, P., Wright, C. I., \& Backman, L. (2005). Age-differential patterns of brain activation during perception of angry faces. Neuroscience Letters, 386, 99-104.

*Fitzgerald, D. A., Angstadt, M., Jelsone, L. M., Nathan, P. J., \& Phan, K. L. (2006). Beyond threat: Amygdala reactivity across multiple expressions of facial affect. Neuroimage, 30, 1441-1448.

*Fitzgerald, D. A., Posse, S., Moore, G. J., Tancer, M. E., Nathan, P. J., \& Phan, K. L. (2004). Neural correlates of internally-generated disgust via autobiographical recall: A functional magnetic resonance imaging investigation. Neuroscience Letters, 370, 91-96.

*George, M. S., Ketter, T. A., Parekh, P. I., Herscovitch, P., \& Post, R. M. (1996). Gender differences in regional cerebral blood flow during transient self-induced sadness or happiness. Biological Psychiatry, 40, 859-871.

*George, M. S., Ketter, T. A., Parekh, P. I., Horwitz, B., Herscovitch, P., \& Post, R. M. (1995). Brain activity during transient sadness and happiness in healthy women. American Journal of Psychiatry, 152, 341-351. 
Goldapple, K., Segal, Z., Garson, C., Lau, M., Bieling, P., Kennedy, S., et al. (2004). Modulation of cortical-limbic pathways in major depression treatment-specific effects of cognitive behavior therapy. Archives of General Psychiatry, 61, 34-41.

*Goldin, P. R., Hutcherson, C. A., Ochsner, K. N., Glover, G. H., Gabrieli, J. D., \& Gross, J. J. (2005). The neural bases of amusement and sadness: A comparison of block contrast and subject-specific emotion intensity regression approaches. Neuroimage, 27, 26-36.

Grafman, J., Schwab, K., Warden, D., Pridgen, A., Brown, H. R., \& Salazar, M. (1996). Frontal lobe injuries, violence, and aggression: A report of the Vietnam Head Injury Study. Neurology, 46, 1231-1238.

*Grandjean, D., Sander, D., Pourtois, G., Schwartz, S., Seghier, M. L., Scherer, K. R., et al. (2005). The voices of wrath: Brain responses to angry prosody in meaningless speech. Nature Neuroscience, 8, 145-146.

*Grosbras, M. H., \& Paus, T. (2005). Brain networks involved in viewing angry hands or faces. Cerebral Cortex, 12, 1087-1096.

*Habel, U., Klein, M., Kellermann, T., Shah, N. J., \& Schneider, F. (2005). Same or different? Neural correlates of happy and sad mood in healthy males. Neuroimage, 26, 206-214.

*Hariri, A. R., Mattay, V. S., Tessitore, A., Fera, F., \& Weinberger, D. R. (2003). Neocortical modulation of the amygdala response to fearful stimuli. Biological Psychiatry, 53, 494-501.

*Harris, L. T., \& Fiske, S. T. (2007). Dehumanizing the lowest of the low: Neuroimaging responses to extreme outgroups. Psychological Science, 17, 847-853.

*Hutcherson, C. A., Goldin, P. R., Ochsner, K. N., Gabrieli, J. D., Barrett, L. F., \& Gross, J. J. (2005). Attention and emotion: Does rating emotion alter neural responses to amusing and sad films? Neuroimage, 27, 656-668.

Ioannidis, J. P., \& Lau, J. (1999). Pooling research results: Benefits and limitations of meta-analysis. Joint Commission Journal on Quality Improvement, 5, 462-469.

*Kesler/West, M. L., Andersen, A. H., Smith, C. D., Avison, M. J., Davis, C. E., Kryscio, R. J., et al. (2001). Neural substrates of facial emotion processing using fMRI. Cognitive Brain Research, 11, 213-226.

*Killgore, W. D., \& Yurgelun-Todd, D. A. (2004). Activation of the amygdala and anterior cingulate during nonconscious processing of sad versus happy faces. Neuroimage, 21, $1215-1223$

*Kilts, C. D., Egan, G., Gideon, D. A., Ely, T. D., \& Hoffman, J. M (2003). Dissociable neural pathways are involved in the recognition of emotion in static and dynamic facial expressions. Neuroimage, 18, 156-168.

*Kimbrell, T. A., George, M. S., Parekh, P. I., Ketter, T. A., Podell, D. M., Danielson, A. L., et al. (1999). Regional brain activity during transient self-induced anxiety and anger in healthy adults. Biological Psychiatry, 46, 454-465.

Kober, H., Barrett, L. F., Joseph, J., Bliss-Moreau, E., Lindquist, K. A., \& Wager, T. D. (2008). Functional networks and cortical-subcortical interactions in emotion: A meta-analysis of neuroimaging studies. Neuroimage, 42, 998-1031.

Krolak-Salmon, P., Hénaff, M. A., Isnard, J., Tallon-Baudry, C., Guénot, M., Vighetto, A., et al. (2003). An attention modulated response to disgust in human ventral anterior insula. Annals of Neurology, 53, 446-453.

Laird, A. M., Fox, P. M., Price, C. J., Glahn, D. C., Uecker, A. M., Lancaster, J. L., et al. (2005). ALE meta-analysis: Controlling the false discovery rate and performing statistical contrasts. Human Brain Mapping, 25, 155-164.

*Lane, R., Reiman, E. M., Ahern, G. L., Schwartz, G. E., \& Davidson, R. J. (1997). Neuroanatomical correlates of happiness, sadness, and disgust. American Journal of Psychiatry, 154, 926-933.

Lang, P. J., Bradley, M. M., \& Cuthbert, B. N. (1990). Emotion, attention, and the startle reflex. Psychological Review, 97, 377-395.

*Lange, K., Williams, L. M., Young, A. W., Bullmore, E. T., Brammer, M. J., Williams, C. R., et al. (2003). Task instructions modulate neural responses to fearful facial expressions. Biological Psychiatry, 53, 226-232.

*Lemche, E. A. E., Surguladze, S. A. A., Giampietro, V. P. B., Anilkumar, A. A., Brammer, M. J. B., Sierra, M. C., et al. (2007). Limbic and prefrontal responses to facial emotion expressions in depersonalization. NeuroReport, 18, 473-477.

*Lennox, B. R., Jacob, R., Calder, A. J., Lupson, V., \& Bullmore, E. T. (2004). Behavioural and neurocognitive responses to sad facial affect are attenuated in patients with mania. Psychological Medicine, 34, 795-802.

Lewis, P. A., Critchley, H. D., Rotshtein, P., \& Dolan, R. (2007). Neural correlates of processing valence and arousal in affective words. Cerebral Cortex, 17, 742-748.

*Liddell, B. J., Brown, K. J., Kemp, A. H., Barton, M. J., Das, P., Peduto, A., et al. (2005). A direct brainstem-amygdala-cortical "alarm" system for subliminal signals of fear. Neuroimage, 24, 235-243.

*Liotti, M., Mayberg, H. S., Brannan, S. K., McGinnis, S., Jerabek, P., \& Fox, P. T. (2000). Differential limbic-cortical correlates of sadness and anxiety in healthy subjects: Implications for affective disorders. Biological Psychiatry, 48, 30-42.

Maren, S. (2001). Auditory fear conditioning increases CS-elicited spike firing in lateral amygdala neurons even after extensive over-training. European Journal Neuroscience, 12, 4047-4054.

*Mayberg, H. S., Liotti, M., Brannan, S. K., McGinnis, S., Mahurin, R. K., Jerabek, P. A., et al. (1999). Reciprocal limbic-cortical function and negative mood: Converging PET findings in depression and normal sadness. American Journal of Psychiatry, 156, 675-682.

Mayberg, H. S., Lozano, A. M., Voon, V., McNeely, H. E., Seminowicz, D., Hamani, C., et al. (2005). Deep brain stimulation for treatment-resistant depression. Neuron, 45, 651-660

*Michalopoulou, P. G., Surguladze, S., Morley, L. A., Giampietro, V. P., Murray, R. M., \& Shergill, S. S. (2008). Facial fear processing and psychotic symptoms in schizophrenia: Functional magnetic resonance imaging study. British Journal of Psychiatry, 3, 191-196.

Miller, E. K., \& Cohen, J. D. (2001). An integrative theory of prefrontal cortex function. Annual Review of Neuroscience, 24, 167-202.

*Mitterschiffthaler, M. T., Fu, C. H. Y., Dalton, J. A., Andrew, C. M., \& Williams, S. C. R. (2007). A functional MRI study of happy and sad affective states induced by classical music. Human Brain Mapping, 28, 177-182.

*Moll, J., de Oliveira-Souza, R., Moll, F. T., Ignacio, F. A., Bramati, I. E., Caparelli-Daquer, E. M., et al. (2005). The moral affiliations of disgust: A functional MRI study. Cognitive and Behavioral Neurology, 18, 68-78.

*Morris, J. S., Friston, K. J., Buchel, C., Frith, C. D., Young, A. W., Calder, A. J., et al. (1998). A neuromodulatory role for the human amygdala in processing emotional facial expressions. Brain, 121, 47-57.

Murphy, F. C., Nimmo-Smith, I., \& Lawrence, A. D. (2003). Functional neuroanatomy of emotion: A meta-analysis Cognitive, Affective, \& Behavioral Neuroscience, 3, 207-233.

Ongur, D., An, X., \& Price, J. L. (1998). Prefrontal cortical projections to the hypothalamus in macaque monkeys. Journal of Computational Neurology, 401, 480-505. 
*Ottowitz, W. E., Dougherty, D. D., Sirota, A., Niaura, R., Rauch, S. L., \& Brown, W. A. (2004). Neural and endocrine correlates of sadness in women: Implications for neural network regulation of HPA activity. Journal of Neuropsychiatry and Clinical Neurosciences, 16, 446-455.

*Paradiso, S., Robinson, R. G., Andreasen, N. C., Downhill, J. E., Davidson, R. J., Kirchner, P. T., et al. (1997). Emotional activation of limbic circuitry in elderly normal subjects in a PET study. American Journal of Psychiatry, 154, 384-389.

*Paradiso, S., Robinson, R. G., Boles Ponto, L. L., Watkins, G. L., \& Hichwa, R. D. (2003). Regional cerebral blood flow changes during visually induced subjective sadness in healthy elderly persons. Journal of Neuropsychiatry and Clinical Neurosciences, 15, 35-44.

*Pardo, J. V., Pardo, P. J., \& Raichle, M. E. (1993). Neural correlates of self-induced dysphoria. American Journal of Psychiatry, 150, 713

*Pelletier, M., Bouthillier, A., Levesque, J., Carrier, S., Breault, C., Paquette, V., et al. (2003). Separate neural circuits for primary emotions? Brain activity during self-induced sadness and happiness in professional actors. NeuroReport, 14, 1111-1116.

Penfield, W., \& Faulk, M. E. (1955). The insula. Further observations on its function. Brain, 78, 445-470.

Pessoa, L., McKenna, M., Gutierrez, E., \& Ungerleider, L. G. (2002). Neural processing of emotional faces requires attention. Proceedings of the National Academy of Sciences, U.S.A., 99, 11458-11463.

Phan, K. L., Wager, T. D., Taylor, S. F., \& Liberzon, I. (2002). Functional neuroanatomy of emotion: A meta-analysis of emotion activation studies in PET and fMRI. Neuroimage, 16, 331-348.

*Phillips, M. L., Bullmore, E. T., Howard, R., Woodruff, P. W. R., Wright, I. C., Williams, S. C. R., et al. (1998). Investigation of facial recognition memory and happy and sad facial expression perception: An fMRI study. Psychiatry Research: Neuroimaging, 83, 127-138.

*Phillips, M. L., Marks, I. M., Senior, C., Lythgoe, D., O’Dwyer, A. M., Meehan, O., et al. (2000). A differential neural response in obsessive-compulsive disorder patients with washing compared with checking symptoms to disgust. Psychological Medicine, 30, 1037-1050.

*Phillips, M. L., Williams, L., Senior, C., Bullmore, E. T., Brammer, M. J., Andrew, C., et al. (1999). A differential neural response to threatening and non-threatening negative facial expressions in paranoid and non-paranoid schizophrenics. Psychiatry Research, 92, 11-31.

*Phillips, M. L., Williams, L. M., Heining, M., Herba, C. M., Russell, T., Andrew, C., et al. (2004). Differential neural responses to overt and covert presentations of facial expressions of fear and disgust. Neuroimage, 21, 1484-1496.

*Phillips, M. L., Young, A. W., Scott, S. K., Calder, A., Andrew, C., Brammer, M., et al. (1998). Neural responses to facial and vocal expressions of fear and disgust. Philosophical Transactions of the Royal Society of London, Series B, Biological Sciences, 265, 1809-1817.

*Phillips, M. L., Young, A. W., Senior, C., Brammer, M., Andrew, C., Calder, A. J., et al. (1997). A specific neural substrate for perceiving facial expressions of disgust. Nature, 389, 495-498.

*Pietrini, P., Guazzelli, M., Basso, G., Jaffe, K., \& Grafman, J. (2000). Neural correlates of imaginal aggressive behavior assessed by positron emission tomography in healthy subjects. American Journal of Psychiatry, 157, 1772-1781.

*Pine, D. S., Grun, J., Zarahn, E., Fyer, A., Koda, V., Li, W., et al. (2001). Cortical brain regions engaged by masked emotional faces in adolescents and adults: An fMRI study. Emotion, 1, 137-147.
Rainville, P., Bechara, A., Naqvi, N., \& Damasio, A. R. (2006). Basic emotions are associated with distinct patterns of cardiorespiratory activity. International Journal of Psychophysiology, 61, 5-18.

*Salloum, J. B., Ramchandani, V. A., Bodurka, J., Rawlings, R., Momenan, R., George, D., et al. (2007). Blunted rostral anterior cingulate response during a simplified decoding task of negative emotional facial expressions in alcoholic patients. Alcoholism, Clinical and Experimental Research, 31, 1490-1504.

*Sambataro, F., Dimalta, S., Di Giorgio, A., Taurisano, P., Blasi, G., Scarabino, T., et al. (2006). Preferential responses in amygdala and insula during presentation of facial contempt and disgust. European Journal of Neuroscience, 24, 2355-2362.

*Sato, W., Kochiyama, T., Yoshikawa, S., Naito, E., \& Matsamura, M. (2004). Enhanced neural activity in response to dynamic facial expression of emotion: An fMRI study. Cognition and Brain Research, 20, 81-91.

*Schafer, A., Schienle, A., \& Vaitl, D. (2005). Stimulus type and design influence hemodynamic responses towards visual disgust and fear elicitors. International Journal of Psychophysiology, 57, 53-59.

*Schienle, A., Schafer, A., Hermann, A., Walter, B., Stark, R., \& Vaitl, D. (2006). fMRI responses to pictures of mutilation and contamination. Neuroscience Letters, 393, 174-178.

*Schienle, A., Schäfer, A., Walter, B., Stark, R., \& Vaitl, D. (2005). Relationship between disgust sensitivity, trait anxiety and brain activity during disgust induction. Neuropsychobiology, 51, 86-92.

*Schienle, A. C., Stark, R., Walter, B., Blecker, C., Ott, U., Kirsch, P., et al. (2002). The insula is not specifically involved in disgust processing: An fMRI study.

NeuroReport, 13, 2023-2026.

*Shapira, N. A., Liu, Y., He, A. G., Bradley, M. M., Lessig, M. C., James, G. A., et al. (2003). Brain activation by disgust-inducing pictures in obsessive-compulsive disorder. Biological Psychiatry, 54, 751-756.

*Sprengelmeyer, R., Rausch, M., Eysel, U. T., \& Przuntek, H. (1998). Neural structures associated with recognition of facial expressions of basic emotions. Philosophical Transactions of the Royal Society of London, Series B, Biological Sciences, 22, 1927-1931.

*Stark, R., Schienle, A., Sarlo, M., Palomba, D., Walter, B., \& Vaitl, D. (2005). Influences of disgust sensitivity on hemodynamic responses towards a disgust-inducing film clip. International Journal of Psychophysiology, 57, 61-67.

*Stark, R., Schienle, A., Walter, B., Kirsch, P., Sammer, G., Ott, U., et al. (2003). Hemodynamic responses to fear and disgust-inducing pictures: An fMRI study. International Journal of Psychophysiology, 50, 225-234.

*Stark, R., Zimmerman, M., Kagerera, S., Schienle, A., Waltera, B., Weygandta, M., et al. (2007). Hemodynamic brain correlates of disgust and fear ratings. Neuroimage, 37, 663-673.

*Takahashi, H., Matsuura, M., Koeda, M., Yahata, N., Suhara, T., Kato, M., et al. (2008). Brain activations during judgments of positive self-conscious emotion and positive basic emotion: Pride and joy. Cerebral Cortex, 18, 898-903.

*Thielscher, A., \& Pessoa, L. (2007). Neural correlates of perceptual choice and decision making during fear-disgust discrimination. Journal of Neuroscience, 27, 2908-2917.

*Vuilleumier, P., \& Pourtois, G. (2007). Distributed and interactive brain mechanisms during emotion face perception: Evidence from functional neuroimaging. Neuropsychologia, 45, 174-194.

Vuilleumier, P., Richardson, M. P., Armony, J. L., Driver, J., \& Dolan, R. J. (2004). Distant influences of amygdala 
lesion on visual cortical activation during emotional face processing. Nature Neuroscience, 11, 1271-1281.

Wager, T. D., Phan, K. L., Liberzon, I., \& Taylor, S. F. (2003). Valence, gender, and lateralization of functional brain anatomy in emotion: A meta-analysis of findings from neuroimaging. Neuroimage, 19, 513-531.

*Wang, L., McCarthy, G., Song, A. W., \& LaBar, K. S. (2005). Amygdala activation to sad pictures during high-field (4 Tesla) functional magnetic resonance imaging. Emotion, 5, 12-22.

Watson, D., \& Tellegen, A. (1985). Toward a consensual structure of mood. Psychological Bulletin, 98, 219-235.

*Whalen, P. J., Rauch, S. L., Etcoff, N. L., McInerney, S. C., Lee, M. B., \& Jenike, M. A. (1998). Masked presentations of emotional facial expressions modulate amygdala activity without explicit knowledge. Journal of Neuroscience, 18, 411-418.

*Wicker, B., Keysers, C., Plailly, J., Royet, J.-P., Gallese, V., \& Rizzolatti, G. (2003). Both of us disgusted in my insula: The common neural basis of seeing and feeling disgust. Neuron, 40, 655-664.

*Williams, L. M., Brown, K. J., Das, P., Boucsein, W., Sokolov, E. N., Brammer, M. J., et al. (2004). The dynamics of cortico-amygdala and autonomic activity over the experimental time course of fear perception. Cognitive Brain Research, 21, 114-123.

*Williams, L. M., Das, P., Liddell, B., Olivieri, G., Peduto, A., Brammer, M. J., et al. (2005). BOLD, sweat and fears: fMRI and skin conductance distinguish facial fear signals. NeuroReport, 16, 49-52.

*Williams, L. M., Phillips, M. L., Brammer, M. J., Skerrett, D., Lagopoulos, J., Rennie, C., et al. (2001). Arousal dissociates amygdala and hippocampal fear responses: Evidence from simultaneous fMRI and skin conductance recording. Neuroimage, 14, 1070-1079.

*Winston, J. S., Vuilleumier, P., \& Dolan, R. J. (2003). Effects of low-spatial frequency components of fearful faces on fusiform cortex activity. Current Biology, 13, $1824-1829$

*Wright, P., He, G., Shapira, N. A., Goodman, W. K., \& Liu, Y. C. (2004). Disgust and the insula: fMRI responses to pictures of mutilation and contamination. NeuroReport, 15, 2347-2351.

Zajonc, R. B., \& McIntosh, D. N. (1992). Emotions research - Some promising questions and some questionable promises. Psychological Science, 3, 70-74. 